University of Redlands

\title{
Analyzing 4-nonylphenol Deposition in the Sierra Mountain Area Using GIS
}

\author{
A Major Individual Project submitted in partial satisfaction of the requirements \\ for the degree of Master of Science in Geographic Information Systems \\ by \\ Omar Ahmed Bugshan
}

Fang Ren, Ph.D., Committee Chair

Douglas Flewelling, Ph.D.

December 2016 
Analyzing 4-nonylphenol Deposition in the Sierra Mountain Area Using GIS

Copyright $@ 2016$

by

Omar Ahmed Bugshan 
The report of Omar Ahmed Bugshan is approved.
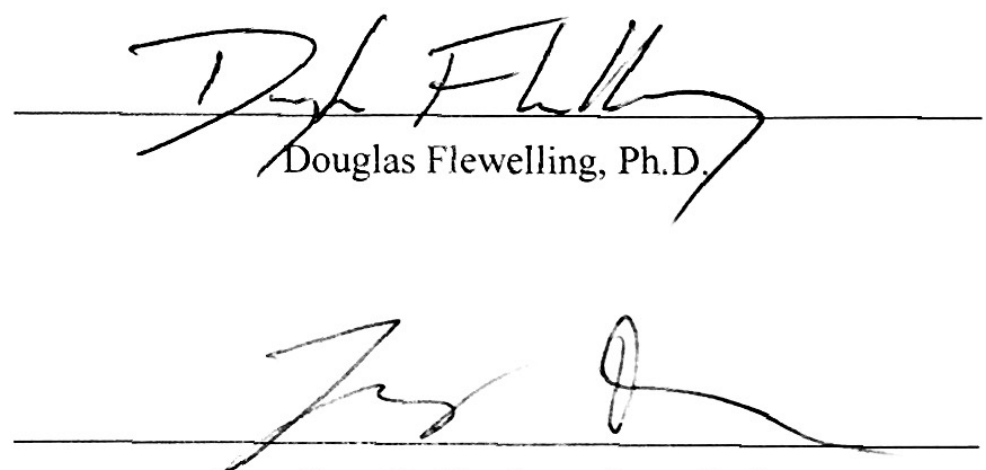

Fang Ren, Ph.D., Committee Chair

December 2016 



\section{Acknowledgements}

At the beginning, I would like to thank Allah for giving me everything to be successful in life. Then, I would like to thank my family for their support through my journey and life. I would like to thank the faculty members of the University of Redlands for all their efforts, guidance, and patience during my two-year program, especially to Dr. Fang Ren and Dr. Ruijin Ma for spending the time to advise and help me with my project.

At the end, I would like to thank my cohort $27.5,27,25$, and 25.5 who were great friends to share their GIS skills with me and for the fun time that we have spent together. These days were the best moments in the United States of America because all of you were part of my happiness. 



\begin{abstract}
Analyzing 4-nonylphenol deposition the Sierra mountain area using GIS project aimed to protect and conserve the eastern side of the Sierra Nevada mountains from a toxic pollutant. The pollutant substance is 4- nonylphenol (4NP) and it is produced from Nonylphenol polyethoxylates that make up $10 \%$ or more of the volume of many pesticides. Furthermore, Fresno County, in California's Central Valley is one of the primary producers of agricultural goods in the United States. Also, it is the number one pesticide user in California. Dr. Rebecca Lyons, the client is trying to find a way to analyze 4NP and how is transported to the fragile ecosystem of the Sierra Nevada mountains. She hypothesized that the topographical shielding has a correlation with the concentration with 4NP. Additionally, a web application was developed to support her research and raise the awareness about the problem and raise the awareness about the problem in order to illuminate the use of this chemical substance.
\end{abstract}





\section{Table of Contents}

Chapter 1 - Introduction 1

1.1 Client 2

$\begin{array}{llr}1.2 & \text { Problem Statement } & 2\end{array}$

$\begin{array}{lll}\text { 1.3 Proposed Solution } & 3\end{array}$

1.3.1 Goals and Objectives $\quad 4$

$\begin{array}{lll}\text { 1.3.2 Scope } & 4\end{array}$

$\begin{array}{lll}\text { 1.3.3 Methods } & 4\end{array}$

$\begin{array}{lll}1.4 & \text { Audience } & 5\end{array}$

1.5 Overview of the Rest of this Report 5

$\begin{array}{ll}\text { Chapter } 2 \text { - Background and Literature Review } & 7\end{array}$

$\begin{array}{lll}2.1 & \text { 4NP Pollution in Sierra Nevada Mountains } & 7\end{array}$

2.1.1 Persistent Organic Pollutant Substances $\quad 8$

2.1.2 Long Range Transport 9

$\begin{array}{lll}2.2 & \text { Web GIS Development } & 11\end{array}$

$\begin{array}{lll}2.2 .1 & \text { Story Maps } & 11\end{array}$

2.2.2 Web Applications 13

$\begin{array}{lll}2.3 & \text { Summary } & 14\end{array}$

Chapter 3 - Systems Analysis and Design 17

$\begin{array}{lll}3.1 & \text { Problem Statement } & 17\end{array}$

$\begin{array}{lll}3.2 & \text { Requirements Analysis } & 17\end{array}$

3.2.1 Functional Requirements 18

3.2.2 Non-Functional Requirements 19

$\begin{array}{lll}3.3 & \text { System Design } & 20\end{array}$ 
$\begin{array}{llr}3.4 & \text { Project Plan } & 21\end{array}$

$\begin{array}{lll}3.5 & \text { Summary } & 21\end{array}$

Chapter 4 - Database Design $\quad 23$

$\begin{array}{lll}4.1 & \text { Conceptual Data Model } & 23\end{array}$

$\begin{array}{lll}4.2 & \text { Logical Data Model } & 24\end{array}$

$\begin{array}{llr}4.3 & \text { Data Sources } & 26\end{array}$

$\begin{array}{lll}4.4 & \text { Data Scrubbing and Loading } & 27\end{array}$

$\begin{array}{llr}4.5 & \text { Summary } & 28\end{array}$

Chapter 5 - Implementation $\quad 29$

5.1 Calculating Topographic Shielding 29

5.2 Publishing Services and Development Outputs 35

$\begin{array}{lll}5.3 & \text { Summary } & 37\end{array}$

Chapter 6 - Results and Analysis $\quad 39$

6.1 Topographic Shielding 39

6.2 Application Interface $\quad 42$

$\begin{array}{lll}6.3 & \text { Summary } & 46\end{array}$

$\begin{array}{ll}\text { Chapter } 7 \text { - Conclusions and Future Work } & 47\end{array}$

$\begin{array}{lll}7.1 & \text { Project Conclusion } & 47\end{array}$

$\begin{array}{lll}7.2 & \text { Future Work } & 47\end{array}$

$\begin{array}{lr}\text { Works Cited } & 49\end{array}$

Appendix A. Python Script $\quad 51$ 


\section{Table of Figures}

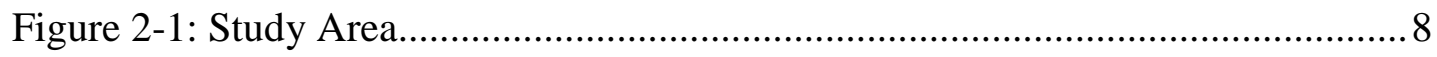

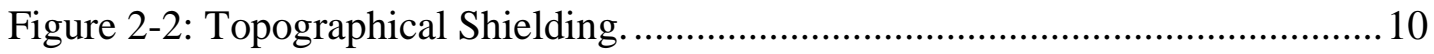

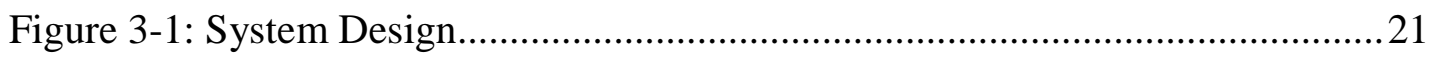

Figure 5-1: Topographical Shielding Equation...............................................2 29

Figure 5-2: DEM and its Derived Slope for the Study Area.................................... 30

Figure 5-3: Location A and The Corresponding Horizontal Point (A') on The

Ridgeline Sierra Nevada Mountains .............................................................. 31

Figure 5-4: Shows The Horizontal Distance From The Ridgeline to The East. The

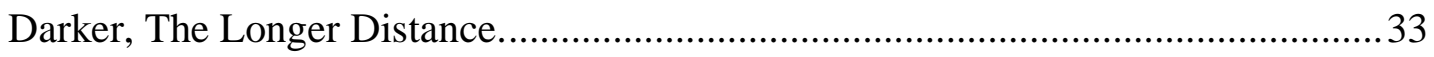

Figure 5-5: Shows the Elevation difference of the Study Area. ............................. 34

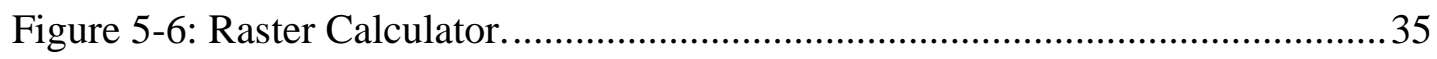

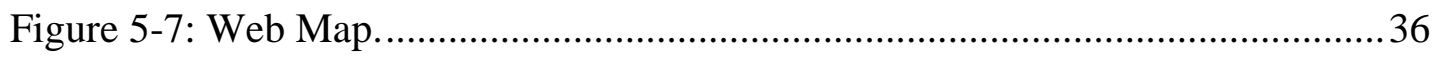

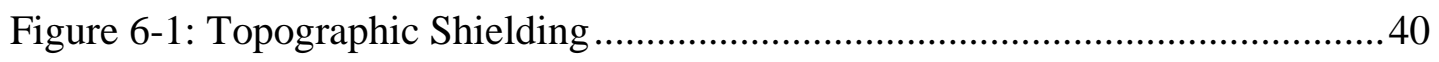

Figure 6-2: The Interface of the Story Map.................................................... 44

Figure 6-3: The Legend of the Story Map................................................... 45

Figure 6-4: The Web Application Interface...................................................... 46 



\section{List of Tables}

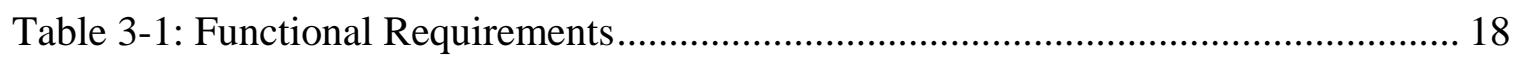

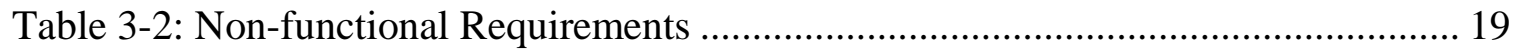

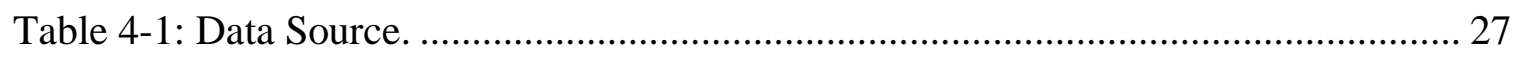

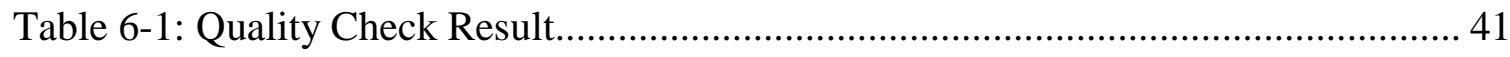

Table 6-2: Compare 4NP Concentration with the Topographical Shield Factor.............. 41 




\section{Chapter 1 - Introduction}

The ecology of the Sierra Nevada is diverse and complex: the plants and animals are a really important part of the scenic beauty of the mountain range. There are many hiking trails, paved and unpaved roads, and vast public lands in the Sierra Nevada for exploring the many different biomes and ecosystems.

Over the last several years, many industrial companies produced pesticides with a lot of chemical components to protect the local harvest. However, over time, these substances turned into endocrine disruptors and became a global environmental issue. These harmful materials have existed in our ecosystem for a long time, and they can be transported through water, air, and the species that live in the polluted area. There is welldocumented literature for (Beyer et al., 2000; Wania and Mackay, 1996) that shows most of the long-range transport of trace organic pollutants from the west side of the Sierras to the east side. These chemical substances are known as persistent organic pollutants (POP).

Dr. Rebecca Lyons from the University of Redlands has designed and built sampling and detector buoys for lakes and rivers. When she moved to Southern California, she conducted an analysis to find out what is in the water within the Sierra Nevada mountains. Unfortunately, she found a series of environmental issues. In the mountain lakes nearby, she found 4-nonylphenol (4NP), an estrogen mimic that acts like a hormone in living systems and alters the delicate balance in ecosystems. Therefore, it is important to find a solution for this problem. Also, based on the earlier work of Dr. Lyons, it seems most likely that far-reaching dust particles were behind the distribution of 4NP across the eastern slopes of the Sierra Nevada. Dust-borne pollutants are of particular concern to 
Southern California because of the current drought. As soils become more desiccated, the movement of pollutants across geographical boundaries is likely to increase. As a result, some of the eastern Sierra Nevada range species such as the Mountain Yellow-Legged Frog (Rana sierrae) are endanger, and it could lead to a loss of another vital species. Also, additional pressure on this ecosystem could prove more devastating to the environment.

This project aimed to help Dr. Lyons test her hypothesis that the pollutants are atmospherically deposited by undergoing long range transport which is affected by local topography. In addition, the project also sought to develop a solution for her to better communicate her research with a broader audience.

\subsection{Client}

Dr. Rebecca Lyons was the client for this project, and she is an Assistant Professor in the Department of Chemistry at the University of Redlands. She has studied novel detection methods for trace organic pollutants for her graduate program, and she is interested in checking the organic pollutants in Southern California. In this project, Dr. Lyons provided the data on the samples she collected in the Sierra Nevada Mountains for 2012 2013 and helped define the scope of the project.

\subsection{Problem Statement}

The Sierra Nevada mountain range has been suffering for many years from toxic pollution but has not gotten adequate attention to be protected and conserved. Dr. Lyons is trying to protect the environment and wildlife from the effects of 4-nonylphenol abuse to ensure an immaculate environment for the future. She was looking for a way to demonstrate the problem to those who are concerned about the environment. Meanwhile, 
Dr. Lyons proposed a concept of "topographic shielding" to explain the transportation mechanism of the pollutant particles and developed a formula to predict pollutant deposition.

\subsection{Proposed Solution}

After a couple of meetings with the client regarding this problem, it was decided that the project problems could be solved by applying geographic analysis and web GIS technology. Specifically, the proposed solution was to perform a raster analysis to see if the localized topography can act as a barrier to incoming atmospheric deposition and to develop web applications to help public understand the environment issue as well as the findings from client's research.

The second goal was to present the locations of the samples that were collected from the study area and to present them in two applications. The application would present these locations that were recorded in a .csv file and other data such as lakes, wind direction, terrain, and the location of the Sierra Nevada Conservancy. The first application would be a story map that would show the problem through slides so that the client and the reader can understand the situation easily. The second application would be a web application that would allow the user to use some tools to query and analyze the data in order to better understand the distribution of the pollutants and its relationship with the wind and geographic characteristics. Moreover, in both of these applications, when the user clicks on one of the samples' locations, the application should display information that is relevant to the location. 


\subsubsection{Goals and Objectives}

The goal of this project was to assist the client to show how the environment is being affected by toxic pollution and to raise public awareness to even eliminate the use of 4nonylphenol. There were two specific objectives. The first objective was to analyze the 4nonylphenol transportation mechanism in the eastern part of Sierra Nevada mountains. The second objective was to develop an application to allow public and researchers to analyze and explore the pollutants and its relationship with the geographic characteristics.

\subsubsection{Scope}

The study area of the project was limited to a specific area in the Sierra Nevada mountains. Three main deliverables include a topographic shielding surface for analyzing pollutant deposition mechanism, one story map for raising public awareness, and a web application for researchers explore the pollutants in the study area with various tools. Both applications would present sample locations that were recorded in a .csv file and other data such as lakes, terrain, and the location of the Sierra Nevada Conservancy. A geodatabase would also be created to organize client's sample data and other datasets relevant to the analysis and visualization.

\subsubsection{Methods}

The project went through a number of phases in order to achieve its objectives, which included performing a raster analysis to predict pollutant deposition and provide interactive mapping applications to show the client's research in the study area.

The first phase was planning. In this phase, the data were collected. The client provided some, and others were obtained from the ArcGIS Online and other sources such as USGS. Also, the client specified the goals and objectives of this phase. 
In the second phase, the data structure was designed by the client. Also, the client specified the desired attributes to be kept in the applications and provided an equation to perform a raster analysis. Data cleaning was also completed in this phase. Once the sample data were processed, geocoding was completed to map these locations on the map.

The third phase focused on developing the two applications and the analysis. The applications were created and developed using ArcGIS Online template. The analysis was performed using ArcGIS Desktop.

The last phase was testing. At this point, the client reviewed the results of the raster analysis and tested the applications to make sure that the outputs were working properly and that the message of the project is clear.

\subsection{Audience}

The intended audience for this project report includes environmentalists, chemists, congress people, politicians, and anyone interested in story map creation and web GIS application development. In addition, this report and application can be useful to anyone who is facing a similar situation or private individual who is trying to illustrate the problem in a modern method.

\subsection{Overview of the Rest of this Report}

The rest of this report will be organized into six chapters, and they will address each part of the project in more detail. Chapter 2 will include the research for previous projects and research that used Esri applications as a solution. Chapter 3 will cover the system design and project planning. Chapter 4 will discuss the conceptual models, the logical models, and the processes of data collection. Chapter 5 will be about the details of 
implementation and the completion of the project. Chapter 6 will illustrate the results of the application. At the end, Chapter 7 will include a project summary, conclusions, and suggestions for future work. 


\section{Chapter 2 - Background and Literature Review}

A literature review was critical for choosing the methods that were used in this project.

The following section describes 4-nonylphenol pollution in Sierra Nevada mountains that include persistent organic pollutant substances, and long range transport respectively, and web GIS development that illustrates story map and web application.

\subsection{NP Pollution in Sierra Nevada Mountains}

Pollution does not concern the United States alone; it is a global issue. More than 90 countries joined the United States and the European community to sign a groundbreaking United Nations treaty in Stockholm, Sweden, in May 2001. Under the treaty, the countries agreed to reduce or eliminate the production, use, and/or release of 12 substances. These substances are known as persistent organic pollutants (POPs), and they are toxic chemicals that negatively affect the health of humans and wildlife around the world. These substances can be transported by water, air, and the species that travel through polluted areas. One of the POP substances, 4-nonylphenol (4NP) is the subject of this project and will be explained in this section. 


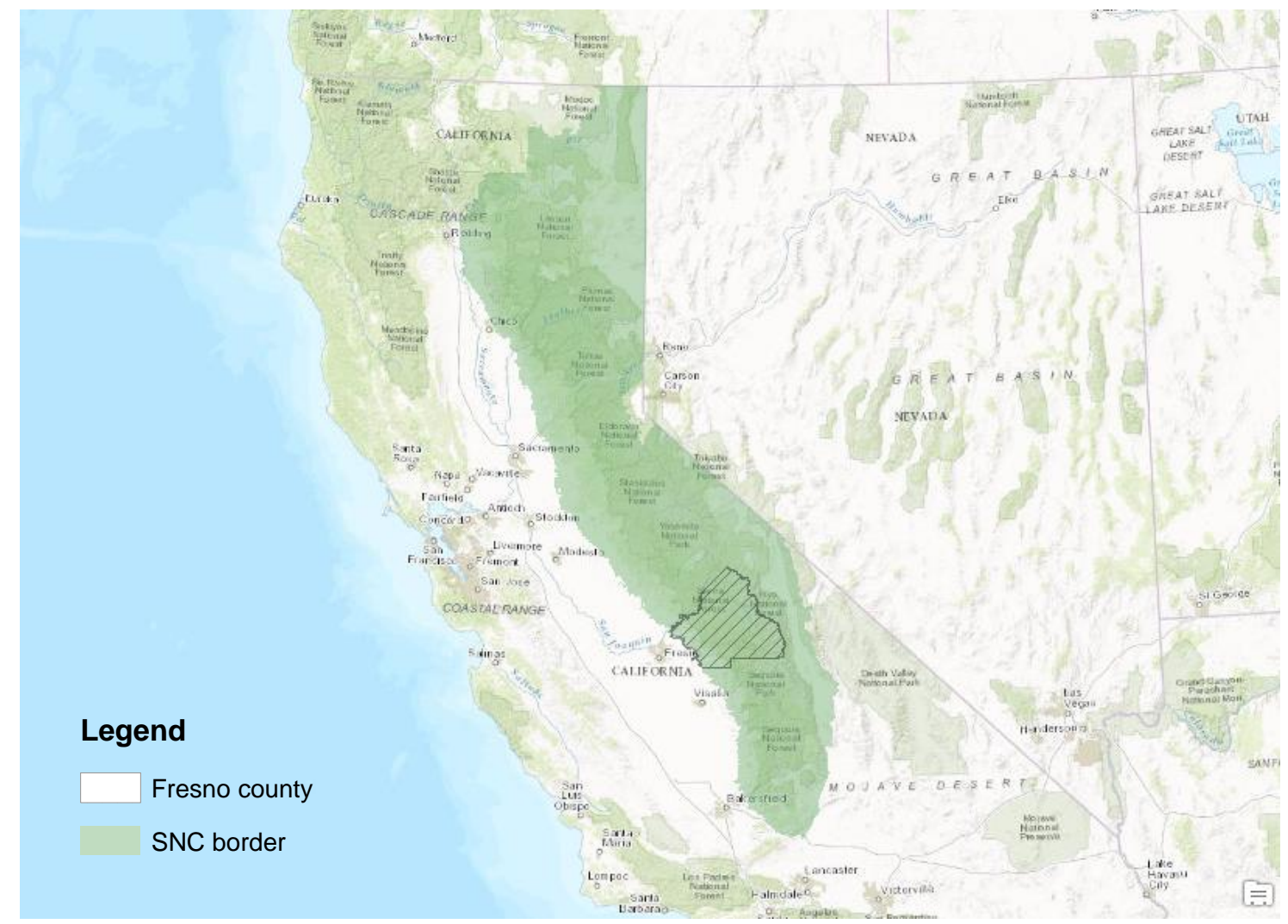

Figure 2-1: Study Area.

The client chose the Sierra Nevada mountains to be the study area for this project for two critical reasons. First, the geographic features of this environment are intriguing, which makes it a good area for studying long range transport (LRT). Second, Fresno County, located between the Pacific Coast and the Sierra Nevada mountains, is one of the primary producers of agricultural goods in the United States (figure 2-1). Also, it is the number one pesticide user in California.

\subsubsection{Persistent Organic Pollutant Substances}

Nonylphenol polyethoxylates have various forms and come in different materials. Its nonionic surfactants are common compounds in cleaning agents, paints, and plastics and make up $10 \%$ or more of the volume of many pesticides. About $80 \%$ of surfactants 
currently in use in North America are nonylphenol polyethoxylates. The substance is created when the nonylphenol polyethoxylate enters the environment and is anaerobically broken down into 4-nonylphenol.

4-nonylphenol is part of a lipophilic compounds group that acts as endocrine disruptors by mimicking one of the strongest female sex hormones, $17-\beta$-estradiol. There are studies that have shown the side effects that can result when the substance enters a living creature. Research (Lalah, 2003; Laws, 2000) has determined that aquatic creatures exposed to 4NP show signs of feminization and suffer from birth defects and higher mortality rates. Also, Bennasroune et al. (2012) stated that the effects on humans may include impaired immune system function. Other research has linked 4NP to nontumorous human cells at the estrogen receptor site, causing cell proliferation and/or cell death (Forte, 2016; Lepretti, 2015). The link between 4NP and various forms of hormone dependent cancers such as ovarian and breast cancer has also been studied (Ren, 1997; Kim, 2015). Currently, it is unknown how long human beings can safely be exposed to 4NP.

\subsubsection{Long Range Transport}

Lyons (2014) published research that explained the deposition patterns and transport mechanisms for the endocrine disruptor 4-nonylphenol, and it has been well documented by (Soares et al., 2008) that the transportation and deposition of airborne particulate matter (PM) is a potential important pathway for the spread of 4NP. These particles have been carrying the 4NP from the west to the fragile ecosystems of the eastern Sierra Nevada mountains, transported by the onshore winds generated along the Pacific Ocean for the majority of the year. The primary source for these particles is wind erosion and 
soil disturbance from agricultural lands. It has been shown that in the southern Sierra

Nevada mountains during the dry season, particulate matter (PM) concentrations increase.

For this reason, Lyons proposed an equation to estimate where the pollutants undergoing long range transport are atmospherically deposited (figure 2-2). She came up with a notion called "topological shielding" that consists of deposition determining factors including elevation, the distance to the mountain range, and the slope.

\title{
DEPOSITION DETERMINING FACTORS
}

\author{
CORRELATION BETWEEN SIZE OF CANYON HEADWALLS AND THE AMOUNT \\ OF NP FOUND IN THEM
}

\section{TOPOGRAPHICAL SHIELDING (T)}

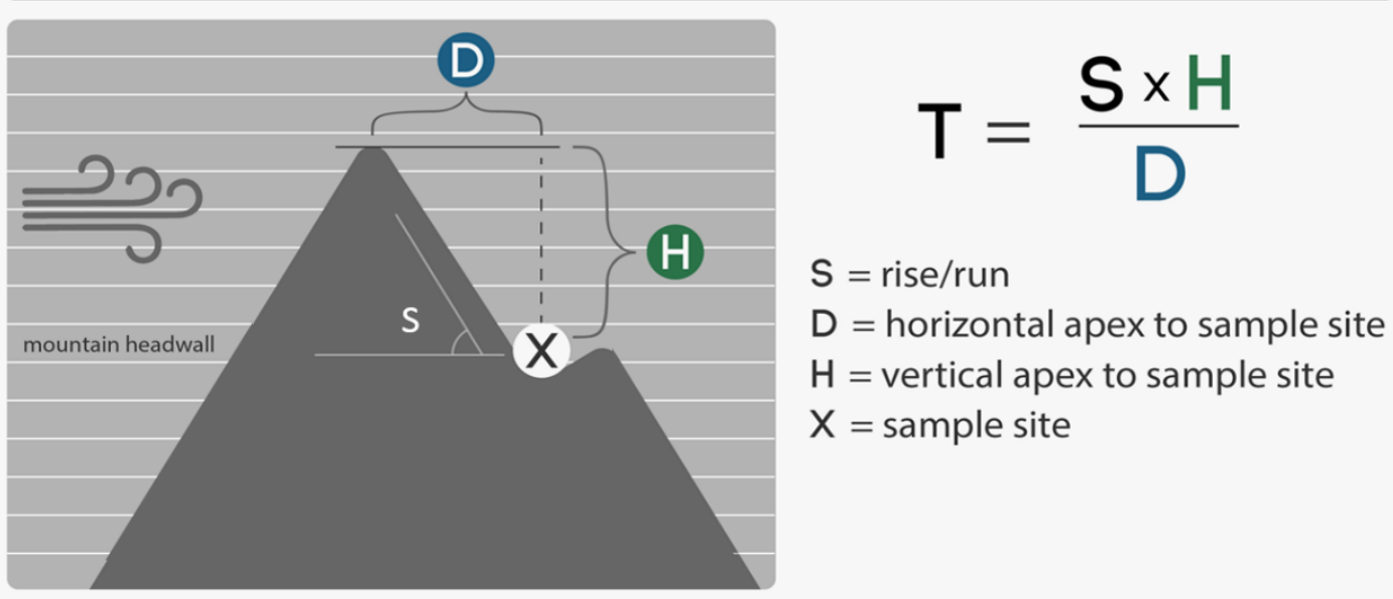

\section{Figure 2-2: Topographical Shielding.}

The equation in Figure 2-2 indicates that these three factors; the distance, slope, and height from the canyons headwall, are the principles to determine the degree of the 
topographical sheltering that characterized the distribution for the eastside of the canyons. Lyons (2014) tested the equation with the samples that she collected from 2012 through 2013. The result of the raster analysis which is the degree of topographical sheltering was compared with the 4-nonylphenol (4NP) concentration for the ice samples along Convict creek drainage. As a result, there was an inverse relationship between 4NP in the snow sample and sheltering. Moreover, 4-NP deposition in snow was reduced to undetectable levels.

\subsection{Web GIS Development}

Currently, web GIS is one of the most useful information distribution systems that involve at least one server and a client. Generally, there is a GIS server and the client can be a web browser, desktop application, or mobile application. Joseph Kerski, a geographer at Esri, believes that education can be transformed by the implementation of digital mapping and the spatial analysis it enables. Likewise, society would benefit from the enhanced ability to make critical decisions pertaining to the important issues of the day, for example, conservation, politics, and climate change. This chapter includes some examples. There are two solutions that support this kind of project, and both of them are Esri ArcGIS Online products. Each of them will be described in this chapter.

\subsubsection{Story Maps}

A story map is an ArcGIS Online product. It is easy to use and it provides a unique way to inform, engage, and inspire people to understand any type of story by using maps, places, locations, or geography. Also, story maps can include text, images, and multimedia such as videos. These features are what make the story map attractive and help the user to understand and feel connected to the story without any misunderstanding 
or confusion. Furthermore, this solution is great for educational purposes. There are many cases that are similar to the client's project that has used this approach.

Lately, the Zika virus has spread through countries, and it can be devastating to the human life. Flanagan (2016) wanted to represent the situation and how far the Zika virus has spread since it first appeared. Therefore, he created a story map for the World Health Organization because the organization has declared that the Zika virus is a global public health emergency. The story map demonstrates how the virus has spread through countries since 1947 to the present day. Moreover, each slide of the story map presents basic information about the number of cases that were found and the location of each infected country.

A similar situation is the Ebola virus epidemic. Flanagan (2014) used the story map method in order to present the whole issue via storytelling. The story map included the first known contact with the disease in 1976 in the Democratic Republic of Congo, and every outbreak for other countries, such as Guinea, Liberia, Sierra Leone, and Nigeria. Moreover, the user can get basic statistics about each outbreak and browse reports from different agencies, all directly within the map. Also, each slide shows the exact location of the city and this information simultaneously.

In another example, TeamDev (2015) wanted to introduce one of the world's oldest diseases — that is associated with grapevines — as a story map for agriculture. Esca is caused by a fungal agent that attacks grapevine wood and leaves, causing great damage to vineyards. For example, this disease has been described in ancient manuscripts like De Agri Cultura by Catone il Censore (160 BC) or Naturalis Historia by Gaio Plinio Secondo (77 AC). TeamDev decided to use the latest technology to present information about this 
disease. The solution was to create a story map because of its power in the education field. Also, TeamDev has included everything related to the disease, from the old and new documents to the story map.

Szukalski (2015) wanted to help an organization present information about whitenose syndrome and how this phenomenon first appeared. White-nose syndrome has spread from the northeastern to the central United States since the winter of 2006. This disease was named for a white fungus that infects the skin of the muzzle, ears, and wings of hibernating bats. Szukalski provided a story map for the organization to support its goal and raise awareness about this disease throughout the country. The story map gives a brief introduction to the problem and has a time slider in order to illustrate the distribution of the disease over time.

A final example is a mosquito-borne disease. Bonino (2016) created a story map that describes malaria and how the disease is transmitted to humans. Also, he explained the eradication of malaria in European Union countries and the concentration of malaria cases in tropical countries. Besides getting this information, the user is able to interact with the map by clicking on countries to get the number of local cases from 2000 to 2014 .

\subsubsection{Web Applications}

The other solution that could be provided for this kind of project, is to create a web application using ArcGIS Online products. What makes this different from the previous solution is that it gives the user access to a lot of ArcGIS Online tools or widgets in order to let the user perform analyses and interact with the data freely. Generally, this application focuses on the ArcGIS tasks. Here are a few cases that were solved by using this approach. 
A project to address Lyme disease was undertaken the California Department of Public Health, Vector-Borne Disease Section (CDPH-VBDS), and its partner agencies. Porse (2013) created a web application focused on the western black-legged tick, a carrier of Lyme disease. This map presents data at the county level. It summarizes data collected on western black-legged ticks from 1985 to 2013 and includes the number of confirmed human Lyme disease cases by county of residence from 2002 to 2011.

Another project used the same method to determine the location of a disease. King (2012) made a web application that shows the locations of yellow-band and black-band diseases in coral reefs in the Caribbean. Also, each point has some information that relates to that location. These diseases are devastating the coral reefs. This project is very important because the coral is already under stress from pollution, overfishing, and climate change.

The last project was created by Esri Story Maps team (2012). They wanted to present diabetes and adult obesity rates among United States citizens. The data is presented on county-level maps. What makes this solution special that the Story Maps team used a slider bar so that the user can compare the obesity and diabetes statistics. Moreover, the user can click on each county to get more information about the estimated percentage of the adult population suffering from these conditions.

\subsection{Summary}

To sum up, this chapter has discussed some of the solutions that can be useful for this kind of projects, and each of them had a couple of cases that provide a variety of models. The first solution was to create a story map because this kind of solution is useful for 
educational purposes. The second one is to create a web application in order to let the user interact with the data and have a different experience from the previous solution. 



\section{Chapter 3 - Systems Analysis and Design}

This chapter demonstrates the system design and requirements that need to be addressed to achieve the objectives of this project. This chapter includes five sections. The first section discusses the problem statement. The second section focuses on the requirements analysis. The third section explains the system design. The fourth section illustrates the project plan. The last section provides a summary of the chapter.

\subsection{Problem Statement}

The ecology of the Sierra Nevada range is in danger because toxic pollution has been increasing for many years. This environment needs to get adequate attention to be protected and conserved. Dr. Lyons was proposing a nonylphenol (4NP) transportation mechanism and searching for a new way to demonstrate the problem to people who are concerned about the environment. However, Dr. Lyons did not have a workflow to test her hypothesis with geographic data and communicate her research with a broader community.

\subsection{Requirements Analysis}

The requirements of the project were discussed with Dr. Lyons during several meetings. The project's requirements were divided into two groups: functional and non-functional. The functional requirements were designated as being what kind of analysis would be conducted, how the web application would be accessible to the client and the user and what the functionalities it would provide. The non-functional requirements were designated as being how the system would operate. 


\subsubsection{Functional Requirements}

The functional requirements of the project describe how the client can use the result of the raster analysis and the users can access the project applications and what functionalities can be used within them. For the raster analysis, the system needed to calculate the topological shielding for the eastern side of the Sierra Nevada mountains based on slope, elevation, and distance from the headwall of the canyon. The result of this analysis would show the relationship between the topographical features and the concentration of 4-nonylphenol.

For the applications, the story map, and the web application would allow the user to use interact with the situation and perform queries to analyze the data in order to better understand the distribution of the pollutants and its relationship with the geographic characteristics. The functional requirements are listed in Table 3-1.

\section{Table 3-1: Functional Requirements}

\begin{tabular}{|l|l|}
\hline $\begin{array}{l}\text { Functional } \\
\text { Requirements }\end{array}$ & Description \\
\hline Raster analysis & $\begin{array}{l}\text { The client asked to perform a raster analysis to } \\
\text { estimate topological shielding effect and show the } \\
\text { relation between the topographical features and the } \\
\text { concentration of 4-nonylphenol. }\end{array}$ \\
\hline $\begin{array}{l}\text { Platform of the } \\
\text { application }\end{array}$ & $\begin{array}{l}\text { The user can access the application from computers } \\
\text { and other devices such as smartphones, and tablets. }\end{array}$ \\
\hline $\begin{array}{l}\text { Various base } \\
\text { maps }\end{array}$ & $\begin{array}{l}\text { The user has the ability to change the base map to a } \\
\text { different one that is associated with the application. }\end{array}$ \\
\hline
\end{tabular}




\begin{tabular}{|l|l|}
\hline $\begin{array}{l}\text { Access to } \\
\text { information }\end{array}$ & $\begin{array}{l}\text { By clicking on points, the user can get information } \\
\text { such as year, season, location, latitude, longitude, and } \\
\text { average 4NP concentration. }\end{array}$ \\
\hline $\begin{array}{l}\text { Information } \\
\text { queries }\end{array}$ & $\begin{array}{l}\text { The user can perform a couple of queries on the data to } \\
\text { get a better understanding of the information. }\end{array}$ \\
\hline $\begin{array}{l}\text { Various chart } \\
\text { options }\end{array}$ & $\begin{array}{l}\text { The user can create a chart in different formats such as } \\
\text { pie or cylindrical shapes or columns, in order to } \\
\text { present specific information. }\end{array}$ \\
\hline $\begin{array}{l}\text { Display of } \\
\text { seasonal trend }\end{array}$ & $\begin{array}{l}\text { The user will find four buttons that show the location } \\
\text { where samples were collected in each season and } \\
\text { compare the trend. }\end{array}$ \\
\hline
\end{tabular}

\subsubsection{Non-Functional Requirements}

The project has non-functional requirements that are associated with how the system will work for the applications. These requirements addressed the technical, and operational that support the functional requirements and display the project as originally anticipated. The non-functional requirements are listed in table 3-2.

\section{Table 3-2: Non-functional Requirements}

\begin{tabular}{|l|l|}
\hline $\begin{array}{l}\text { Non-functional } \\
\text { Requirements }\end{array}$ & Description \\
\hline $\begin{array}{l}\text { Sending the result of } \\
\text { analysis }\end{array}$ & The client will receive the result as a map. \\
\hline Using Esri templates & $\begin{array}{l}\text { The template of the project should be from the Esri } \\
\text { Story Map's selection of templets. }\end{array}$ \\
\hline Publishing the project & $\begin{array}{l}\text { The user can find the project in Esri ArcGIS Online } \\
\text { gallery. }\end{array}$ \\
\hline
\end{tabular}




\begin{tabular}{|l|l|}
\hline $\begin{array}{l}\text { Non-functional } \\
\text { Requirements }\end{array}$ & Description \\
\hline $\begin{array}{l}\text { Sending the result of } \\
\text { analysis }\end{array}$ & The client will receive the result as a map. \\
\hline $\begin{array}{l}\text { Sharing the } \\
\text { application }\end{array}$ & $\begin{array}{l}\text { The client will have the authority to maintain, } \\
\text { update, and republish the project. }\end{array}$ \\
\hline
\end{tabular}

\subsection{System Design}

The system was designed based on the client's requirements (Figure 3-1). There are five components that the project relies on. The first component is input data. In this project, data were obtained from various sources and they were saved in a geodatabase. The geodatabase was designed to host all of the datasets in order to optimize the performance and improve usability. The second component is analysis. With this geodatabase, raster analysis was conducted and a python script was developing to automate the analysis flow. The third component is publishing the data. They were published as multiple feature services in ArcGIS Online organizational account of the University of Redlands. The fourth component is creating web maps. These maps will host the published features to symbolize and illustrate them. The last component is an application. The application would integrate web map feature services in order to represent them in a specified interface design which was requested by the client. 


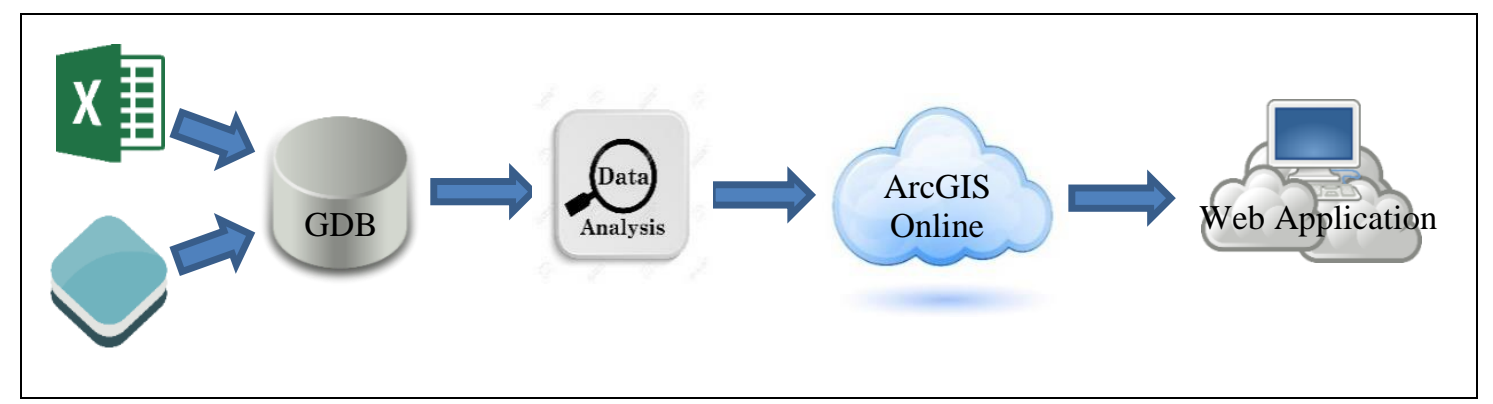

Figure 3-1: System Design

\subsection{Project Plan}

The project was divided into four phases, and each of them had a few tasks. The first phase of the project was planning, which included meeting the client in order to define the variables of the project such as the scope of the project, goals, objectives, and examining the data. The second phase was designing, it was about identifying the structure of the data; this phase was accomplished with the assistance of the client. The third phase was performing the analysis. This analysis would define the role of topographical features toward the 4NP concentration. The fourth phase was development. It included the technical work of creating the maps and the symbology for the project. The last phase was examination and testing, performed by the client. Also, the project would need to be completed and documented for submission to the client by the scheduled deadline, December 2016.

\subsection{Summary}

This chapter has defined the system analysis and design boundaries of the project, starting with presenting the problem; next designating the functional and non-functional requirements; then, designing the system; and, finally, providing a plan for the project. Also included are three tables, and each of them conveys more information related to each section. 



\section{Chapter 4 - Database Design}

Chapter 4 discusses the database design and the data that were implemented in the project. The conceptual data model is described in section 4.1 , Section 4.2 outlines the logical data model. Data sources are included in section 4.3, data collection is described in section 4.4, and data scrubbing and loading are discussed in section 4.5. Finally, section 4.6 summarizes chapter 4 .

\subsection{Conceptual Data Model}

The conceptual data model is used to explain the project plan and describes the highest level of relationships between the different entities of the project. Figure 4-1 illustrates the conceptual data model that the client proposed to estimate deposition of the $4 \mathrm{NP}$ pollutant particles for the study area. This model identifies the data required to be implemented in the project in order to solve the client's problem.

There is a relationship between the three factors - the slope, the height, and the distance - and the concentration of the toxic substance and the topographical shielding. For the first factor, when the slope has a low value that indicates a low value of topographical shielding and a high value of 4NP concentration. However, when the steepness of slope is high that would indicate a high value for topographical shielding and a low value for 4NP concentration. For the second factor, when the drop in height has a high value, that would indicate a high value for the topographical shielding and low value for the 4NP concentration and vice versa. Both of the first two factors are numerators in the equation of the raster analysis. 
The last factor in the equation of the raster analysis is distance. It is the denominator of the equation: when it has a high value, that would indicate a low value for the topographical shielding and a high value for 4NP concentration.

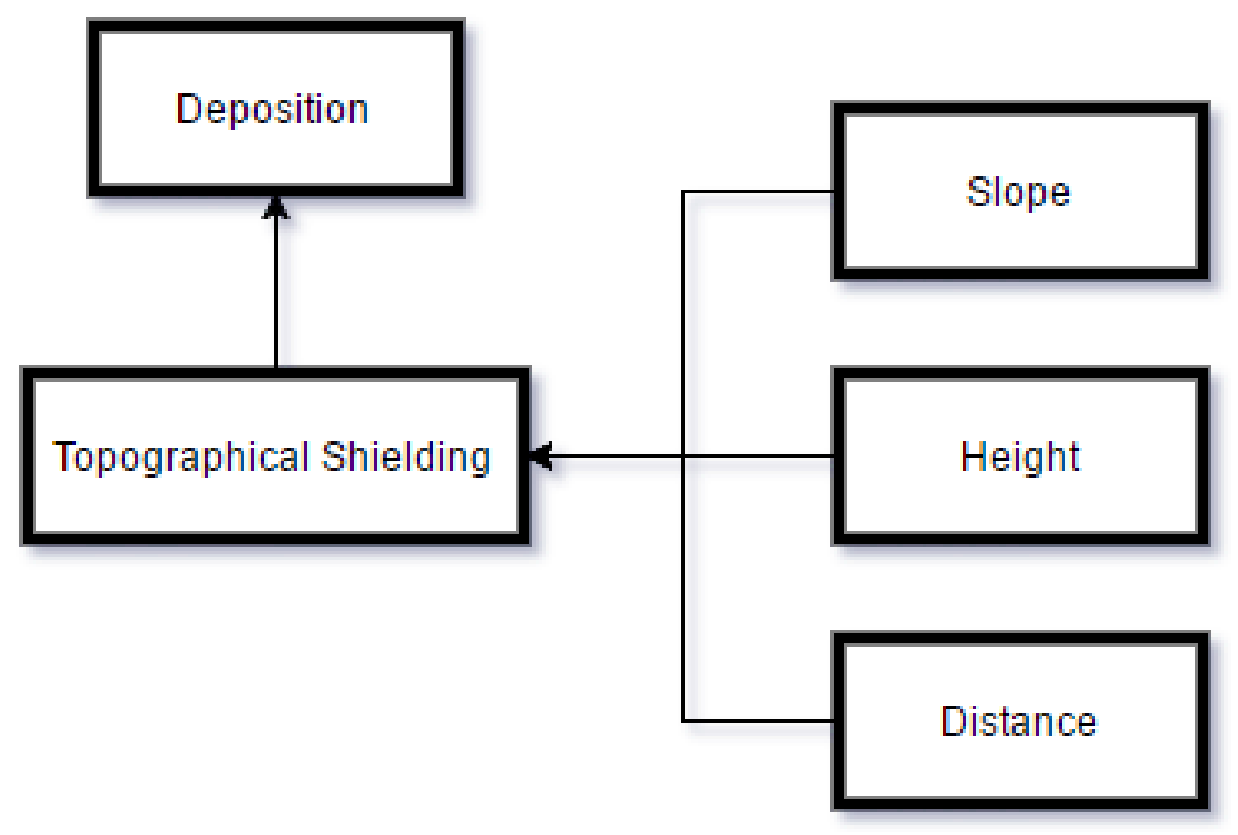

\section{Figure 4-1: Conceptual Data Model.}

In summary, it is hypothesized that dense deposition occurs more likely at the lower elevations that are far from the ridgeline and has steep slopes. These three local geographic variables are combined into a so-called "topographic shielding" factor that has an inverse relationship with the deposition. Therefore, the higher the topographical shielding is, the less 4NPconcentration.

\subsection{Logical Data Model}

The logical data model represents a geodatabase of the project. The logical data model includes more details than the conceptual data model. The data of this project were 
organized and collected in Esri's file geodatabase using ArcGIS for Desktop. Figure 4-2 shows the geodatabase structure.

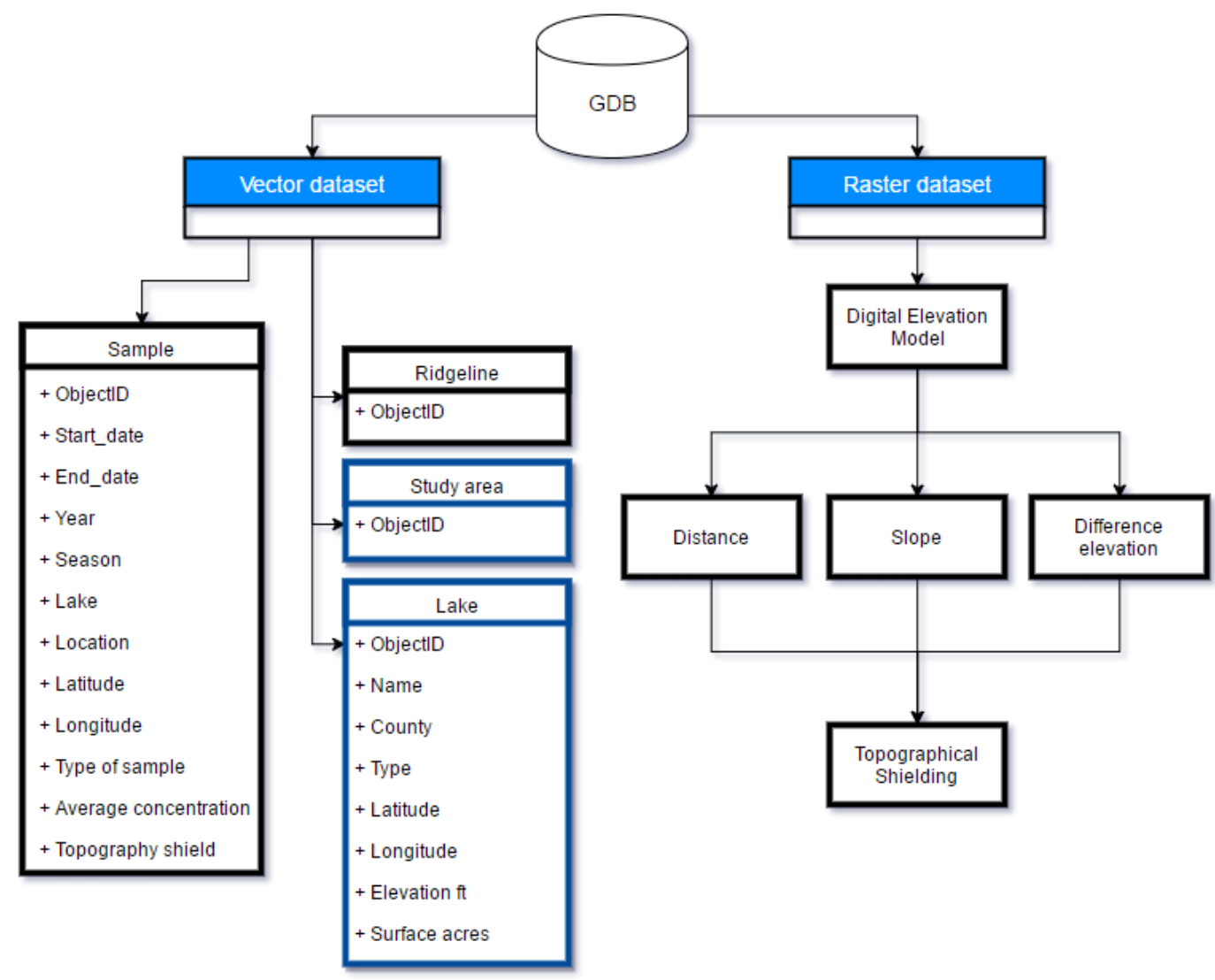

Figure 4-2: Logical Data Model.

The geodatabase contains two datasets. One dataset contains four vector feature classes. The first feature class is a point feature class that contains the sample locations where measurements were collected. The second feature class is a polyline feature class for the ridgeline of the Sierra Nevada mountain range. The third feature is a polygon feature class showing the lakes' locations. The last feature is a polygon feature class that shows the location of the study area. The last two feature classes in this dataset were nonanalytical features. The other dataset contained the raster layers that were used in the 
analysis. The first raster layer is the DEM of the study area, with which the rest of the raster layers were calculated. There were three raster surfaces used in the analysis: slope, the horizontal distance from the ridgeline, and the elevation difference between the study and the ridgeline. The final raster layer is the final output for topographic shielding surface.

\subsection{Data Sources}

The project had four primary resources for the datasets (Table 4-1). The first resource was the client who provided the list of where samples were located. The second resource was Lisa Benvenuti from Center for Spatial Studies and this file was created by Steve Denowski, Greg Allord, Curtis Price, Ken Lanfear and David Lorenz, in addition to other colleagues within the U.S. Geological Survey. The third resource was United States Geological Survey (USGS) website where the digital elevation model was downloaded from the National Map Viewer. The fourth resource was the State of California's Sierra Nevada Conservancy's website where the California Lakes dataset was available. The rest of the data were created using ArcGIS for Desktop. 
Table 4-1: Data Source.

\begin{tabular}{|l|l|l|}
\hline Dataset & Data Source & Data Type \\
\hline Samples & The Client & Excel Spreadsheet \\
\hline Ridgeline & $\begin{array}{l}\text { Center for Spatial Studies } \\
\text { at Redlands }\end{array}$ & Polyline \\
\hline Digital Elevation Model & $\begin{array}{l}\text { USGS National Map } \\
\text { Application }\end{array}$ & Raster \\
\hline California Lakes & $\begin{array}{l}\text { State of California-Sierra } \\
\text { Nevada Conservancy }\end{array}$ & Polygon \\
& & \\
\hline
\end{tabular}

\subsection{Data Scrubbing and Loading}

Since the data were obtained from different resources, data scrubbing was essential for preparation and storage in the geodatabase. Most of the data, such as samples' locations, lakes, and ridgeline, had many attributes that were not needed for the project, and all of the data had different coordinate systems. Therefore, several attributes were deleted, as well as all the data, were projected into an optimal projection which is NAD_1983_2011_StatePlane_California_IV_FIPS_0404_Ft_US coordinate system and stored the project geodatabase.

Dr. Lyons provided an Excel spreadsheet that contained much information about where the samples were collected, but she chose only certain information to be presented in the project such as start date, end date, year, season, lake, location; it refers to locations in the eastern side of Sierra Nevada mountains that was specified by Dr. Rebecca and her colleges, latitude, longitude, type of sample, and average concentration. The other 
attributes were omitted because they were empty or the public won't understand them, such as elevation, description, file, site, unique identifier, drainage, abbreviation, average mass, and average area. Then, the spreadsheet was uploaded into ArcGIS to be visualized and symbolized (figure 5-2) and there are eighty-six samples in the feature class. Also, lakes and ridgeline data were imported into ArcGIS they were symbolized as well.

\subsection{Summary}

This chapter described the conceptual and logical data models for the raster analysis and the development of the web application. Also, the chapter addressed the data sources and covered how the data was collected and prepared for storage in the project geodatabase. 


\section{Chapter 5 - Implementation}

Chapter 5 addresses the steps that were implemented in this project. This chapter includes three sections, and each one of them explains the process of the implementation. Section 5.1 describes calculating topographic shielding. Publishing services and development outputs are covered in section 5.2. Section 5.3 summarizes the chapter.

\subsection{Calculating Topographic Shielding}

The topographic shield was calculated based on the client's equation (Figure 5-1), and it relies on three factors, which have been illustrated under section 4.1-Conceptual Data Model. The first factor of the equation is the slope (Figure 5-2). This factor can be created based on a digital elevation model (DEM) of the study area by using ArcToolbox in ArcGIS for Desktop. The slope is measured in percent (rise/horizontal run).

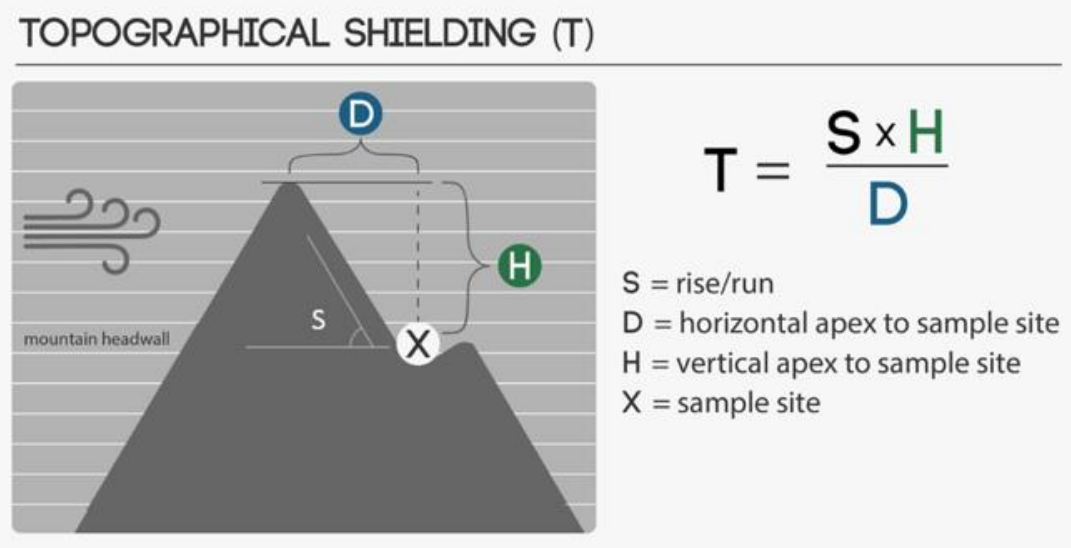

Figure 5-1: Topographical Shielding Equation. 


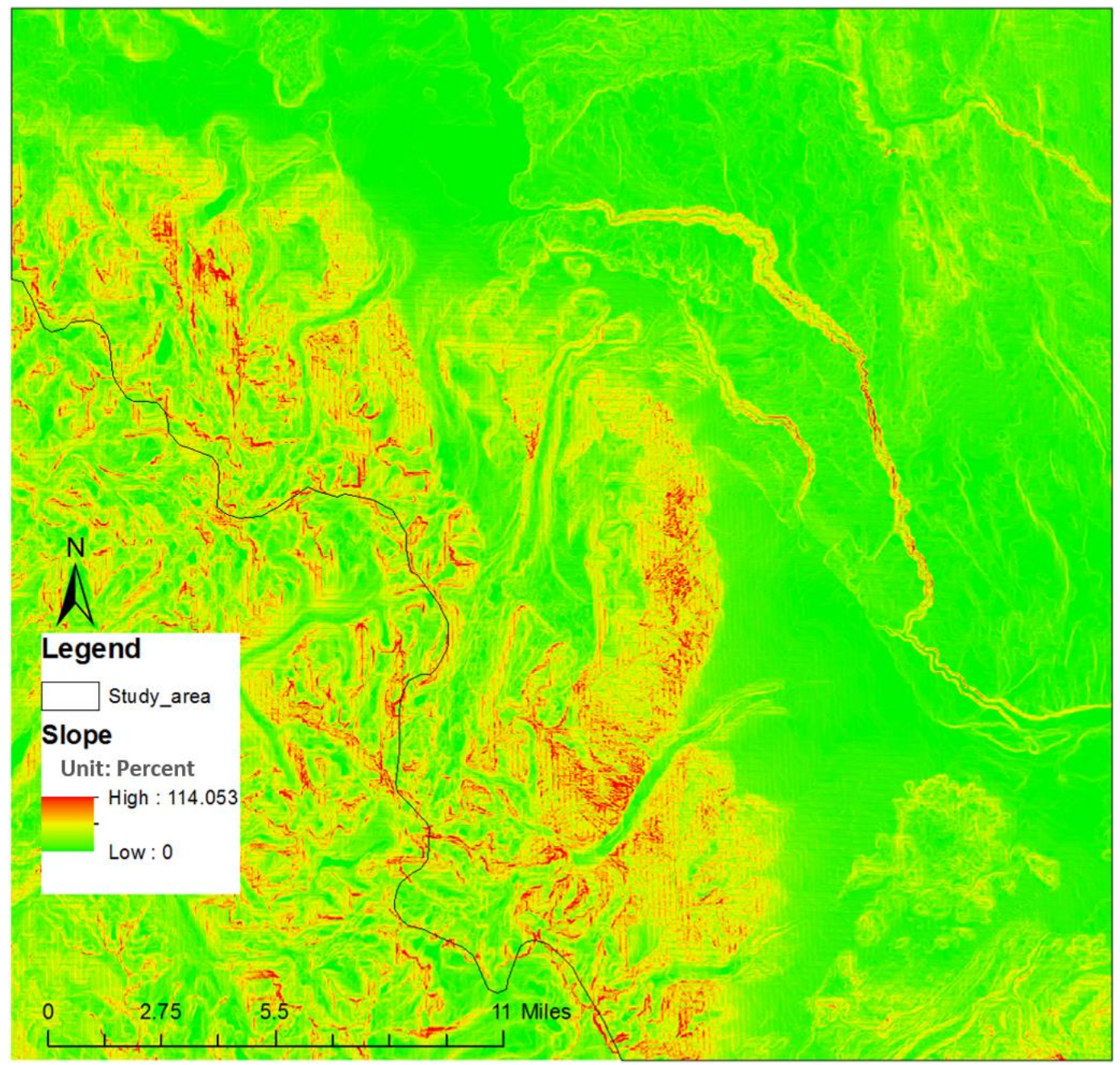

Figure 5-2: DEM and its Derived Slope for the Study Area.

The second factor is the horizontal distance from the headwall (A') to any location (A) in the study area as shown in Figure 5-3. The third factor is the height from the headwall (A') to the location of A in the Figure 5-3. Put differently, the height is the elevation difference between location $\mathrm{A}$ and the corresponding horizontal point ( $\left.\mathrm{A}^{\prime}\right)$ on the ridgeline of the Sierra Nevada mountains. 


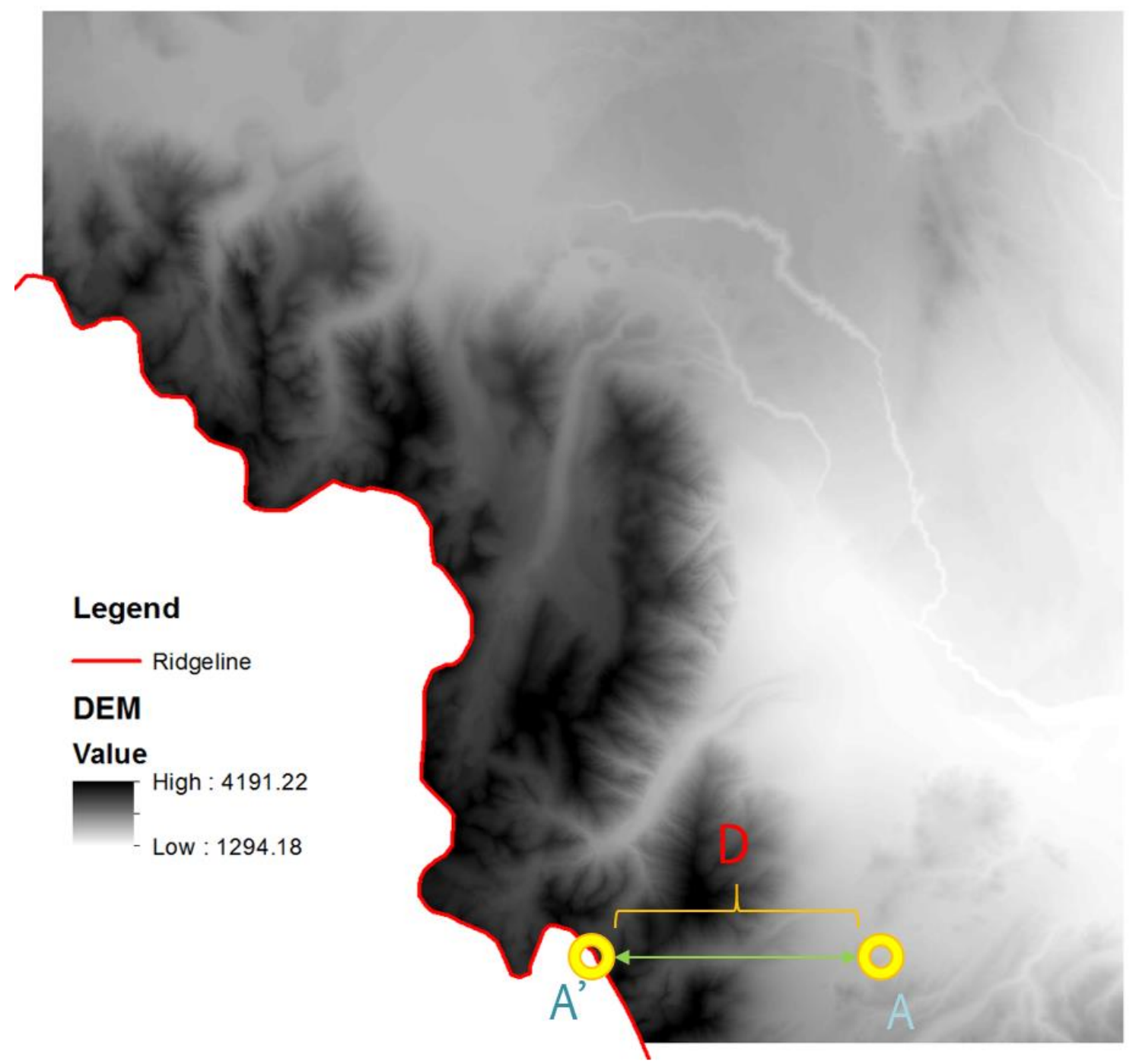

\section{Figure 5-3: Location A and The Corresponding Horizontal Point (A') on The Ridgeline Sierra Nevada Mountains}

To automate the calculation process, a Python script was developed by Dr. Ruijin Ma. The two raster layers are treated as two matrices and the horizontal distance can be obtained by comparing the column difference for any cell to the cell of the ridgeline on the same row. The difference in elevation is calculated by subtracting the elevation of any cell from that of the cell of the ridgeline on the same row. Only cells on the east side of the ridgeline are considered due to client's hypothesis. The pseudocode is given below and the script is included in Appendix A. The flow of the process is illustrated below: 
Input: DEM and Ridgeline raster in the same dimension.

Output: One distance raster and one elevation difference raster.

For each row $\mathrm{r}$ in ridgeline raster:

For each column $\mathrm{c}$ in the row:

If the pixel value is 0 :

Continue

Else,

For each column cc after c:

Distance $=(\mathrm{cc}-\mathrm{c}) *$ spatial resolution

Elevation difference $=\mathrm{DEM}$ at $\mathrm{cc}-\mathrm{DEM}$ at $\mathrm{c}$

Write distance and elevation difference to the output raster respectively. 
The input for the Python script includes two raster layers: the DEM and the ridgeline. To obtain the ridgeline raster layer, Extract by Mask tool was applied to extract ridgeline from the DEM so that these two raster layers have the same dimension. The output the script contains two raster layers: the horizontal distance from the ridgeline and the elevation between any location and the ridgeline. Figure 5-4 shows the distance from the ridgeline to the east of the study area.

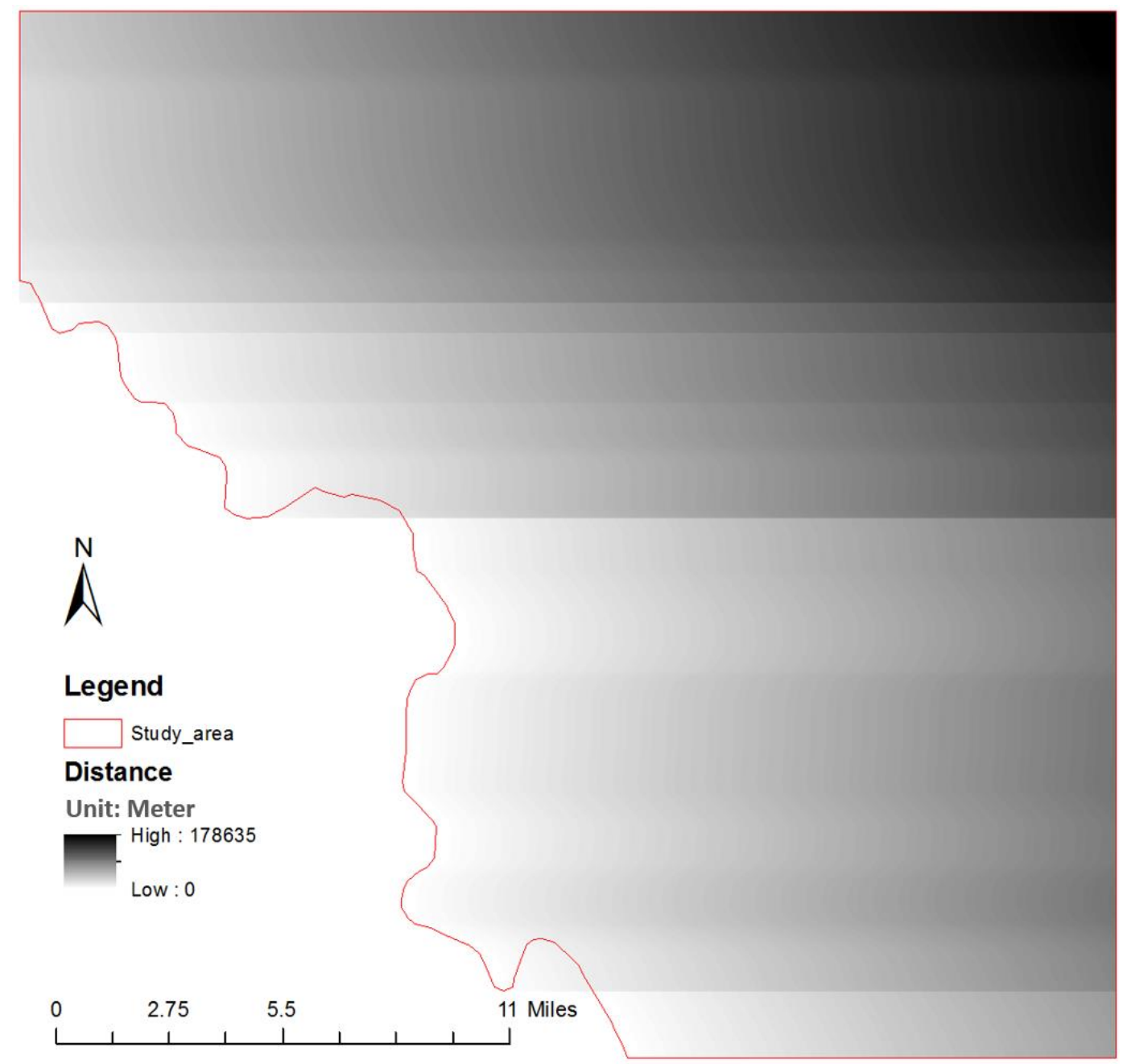

Figure 5-4: Shows The Horizontal Distance From The Ridgeline to The East. The Darker, The Longer Distance. 
Figure 5-5 shows the elevation difference from the ridgeline to the east. It is worth pointing out that some cells take negative values, which suggests that these places are actually higher than the ridgeline. Therefore, the difference becomes negative. The interpretation of the negative differences should be further studied.

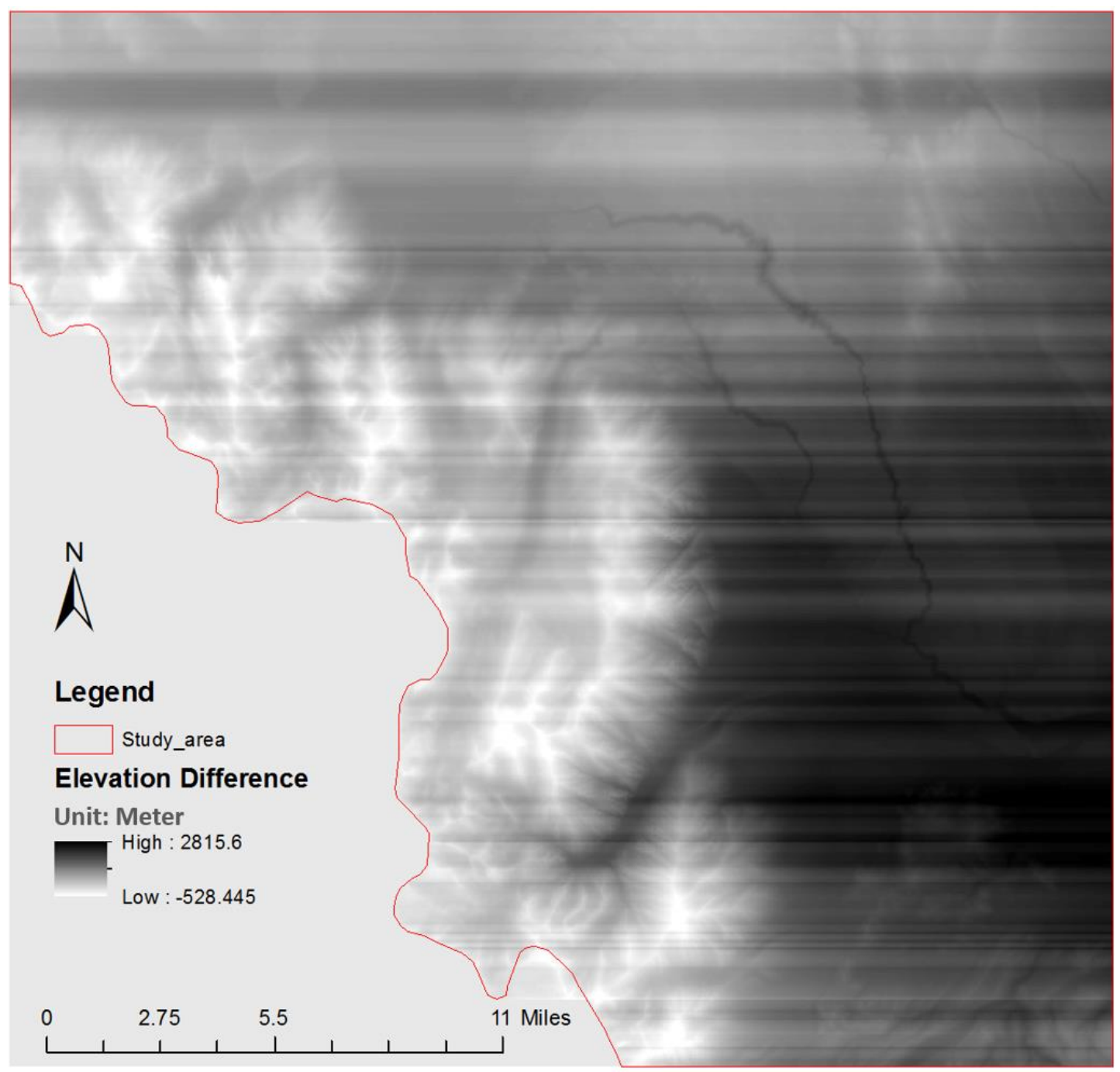

Figure 5-5: Shows the Elevation difference of the Study Area.

Once all three factors were calculated, the Raster Calculator tool was used to create the final composite topographic shielding raster layers (Figure 5-6). 


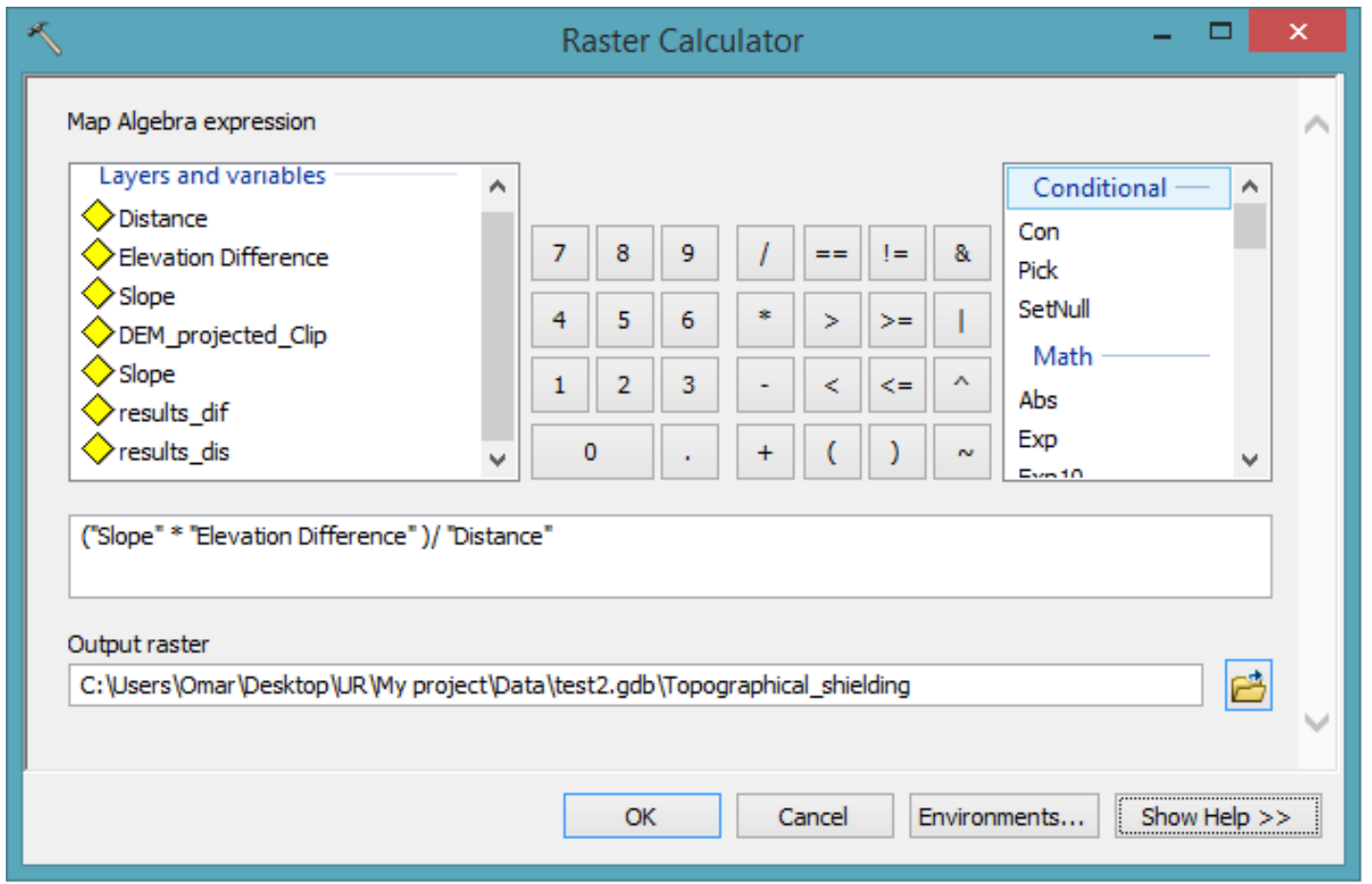

Figure 5-6: Raster Calculator.

The final unit of the layer is the same as the slope unit. Further, the topographic shielding values at the sample locations were extracted with the Extract by Points tool and compared to the measurements. The result of the topographic shielding and comparison will be discussed in Chapter 6.

\subsection{Publishing Services and Development Outputs}

After storing the points, lines and polygons in the project file geodatabase, the feature classes needed to be published as map services to be used in a story map. The data can be published through ArcGIS for Desktop or ArcGIS Online, either of which can be used with the University of Redlands' organizational account. For this project, ArcGIS for Desktop was used for publishing the data. Moreover, ArcGIS Desktop would allow the users to publish the features through two types of services. Tiled map and feature service. Based on the purposes of the applications, feature service was chosen. 
The procedure for publishing the feature service from an ArcGIS for Desktop organizational account consists of three steps. At the beginning, the user has to sign in with an ArcGIS organization's URL. For this project, signing in was done through the University of Redlands enterprise account. Then, the map content is shared, using chosen capabilities that the client wanted to be enabled and the feature service was specified. The operations were chosen based on the objectives of the project. And finally, the MXD file needs to be analyzed in order to find any errors or warnings before the layers were published.

After the data were published, it was time to collect the published features into a single web map (Figure 5-7) and to create and configure the pop-ups for the operational layers. Also, the data visibility setting was customized to match the client's preferences.

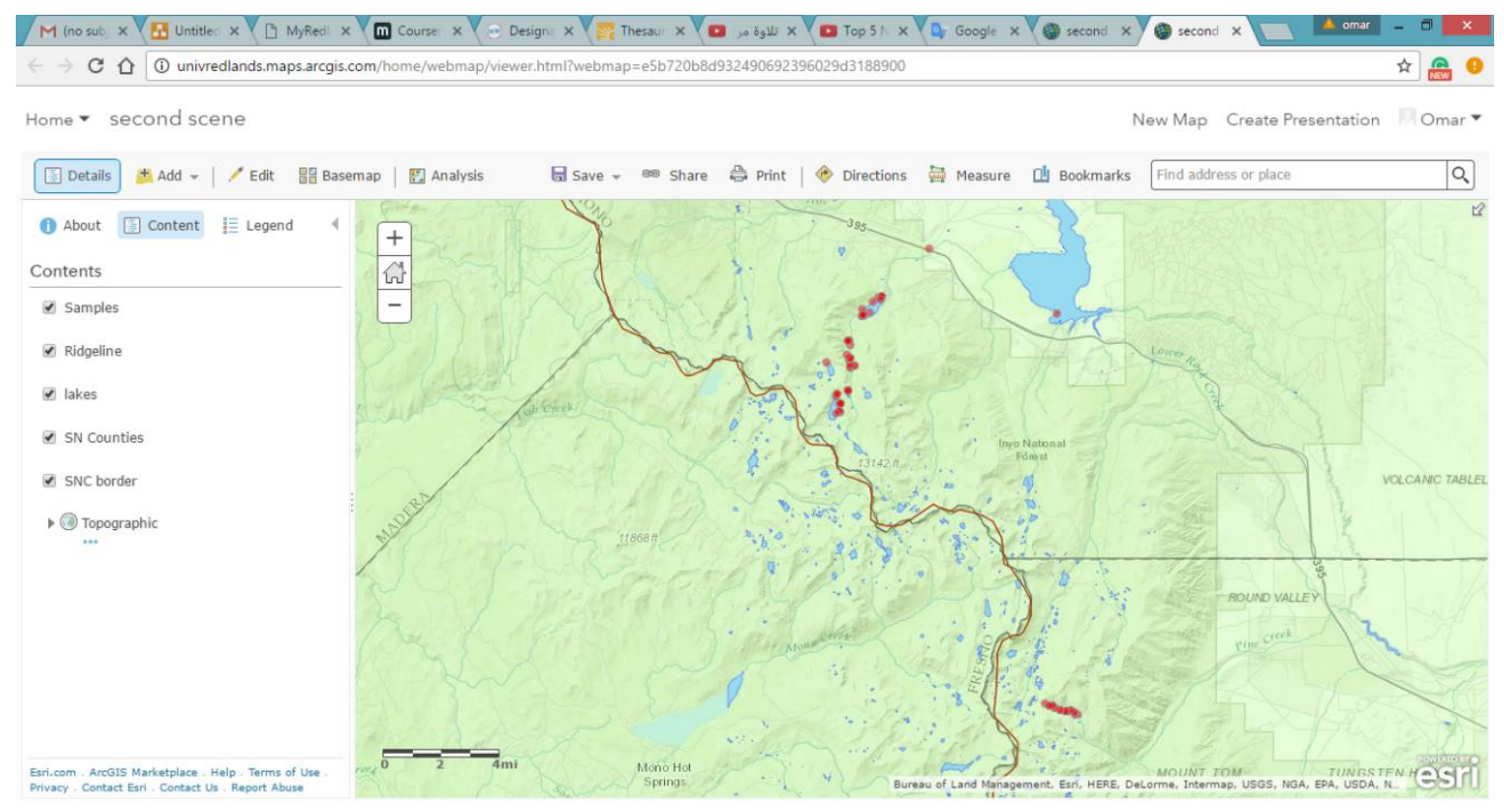

Figure 5-7: Web Map.

The next step is to choose the application, which would make the web map interactive. For the story map, the client chose one of the Esri Story Maps templates in 
ArcGIS Online. Each slide of the story map presented information about 4-nonylphenol and related maps. All the features have been incorporated into interactive story maps.

For creating the web application, there are two editions of Web Appbuilder for ArcGIS to choose from. The first is the developer edition. This edition provides more capabilities to build and customize the tools, but it needs to be downloaded and hosted on the local server. The other edition is the integrated edition, which requires no programming skills and provides customized tools that could be applied on the data of this project. was created by using Web Appbuilder for ArcGIS. It was used for the interface and the functionality of the web application. Both the story map and web application will be presented in chapter 6 .

\subsection{Summary}

This chapter discussed the methodology that was used in the project to reach the final outcomes. Section 5.1 covered the calculating topographic shielding. Section 5.2 discussed the publishing services and the development of the outputs. 



\section{Chapter 6 - Results and Analysis}

This project has two outputs. The first output is the topographic shielding raster surface that shows the shielding effect at the eastern Sierra Mountain area. With this output, the hypothesis about the mechanism of long transport of 4NP pollutant is examined. The second output is web application an application for the Wind Shadow Map that allows the public to learn the environmental issue, thereby the public awareness of this issue will be raised.

\subsection{Topographic Shielding}

One of the main goal of this project was to verify how 4-nonylphenol (4NP) concentrations correlated with topographical features for the eastern Sierra Nevada mountains range. The analysis was performed using Python and Raster Calculator based on three factors, which have been discussed in Chapter 5.

The topographic shielding raster was shown in Figure 6-1. These values identify a transportation corridor, spots in the topographical shield that have enough gap in the headwall of the Sierra Nevada mountains that toxic pollutants go through it, and on it the eastern side of the Sierra Nevada mountains. The result of this equation is shown in figure 6-1. 


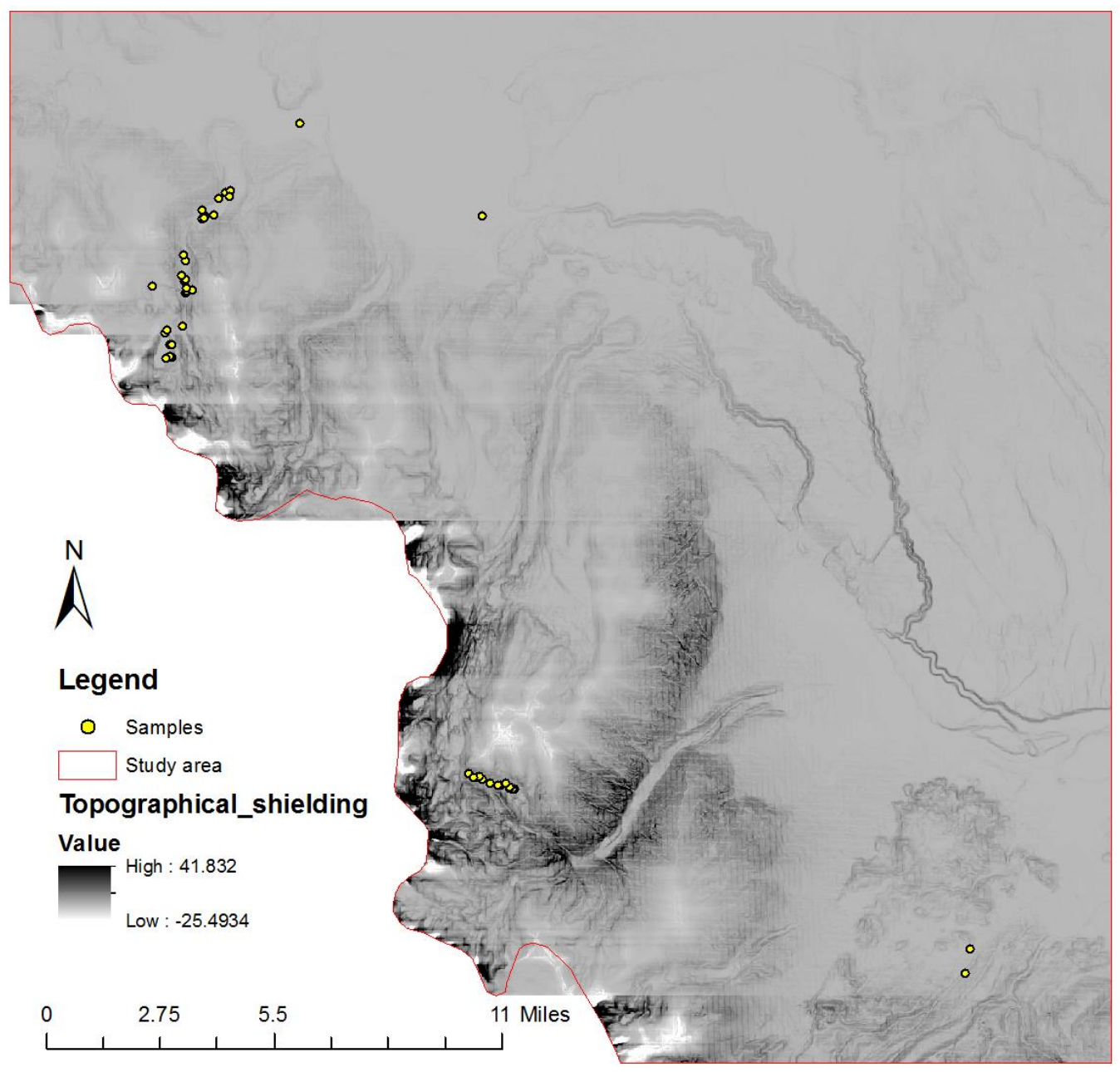

\section{Figure 6-1: Topographic Shielding}

After performing the raster analysis quality check was essential in order to evaluate and determine the accuracy of the values of the topographical shielding. The quality check was applied on six points that were chosen randomly. Table 6-1 summarizes the comparison result. It shows that two topographical shielding results are the same from both approaches. 
Table 6-1: Quality Check Result

\begin{tabular}{|c|c|c|c|c|}
\hline Slope & Height & Distance & Result & $\begin{array}{c}\text { Topographical } \\
\text { Shielding }\end{array}$ \\
\hline 3.337649 & 277.984375 & 27684.82422 & 0.033513461 & 0.033513 \\
\hline 1.329278 & 1808.89722 & 65354.33984 & 0.036792159 & 0.036792 \\
\hline 16.6575 & 857.780029 & 45929.57813 & 0.311095097 & 0.311095 \\
\hline 28.01633 & 482.944336 & 32404.86133 & 0.417540109 & 0.41754 \\
\hline 9.138247 & 631.830566 & 14069.33691 & 0.410383503 & 0.410384 \\
\hline 0 & 867.487793 & 50014.22656 & 0 & 0 \\
\hline
\end{tabular}

Furthermore, it was necessary to compare the topographical shielding values at the sample locations to the measurements obtained from these sample locations. In doing so, the hypothesis about the impact of topographic shielding on 4-NP deposition can be examined. Table 6-2 lists the two variables.

Table 6-2: Compare 4NP Concentration with the Topographical Shield Factor.

\begin{tabular}{|c|c|c|c|}
\hline $\begin{array}{c}\text { Average } \\
\text { Concentration }\end{array}$ & $\begin{array}{c}\text { Topographical } \\
\text { Shielding }\end{array}$ & $\begin{array}{c}\text { Average } \\
\text { Concentration }\end{array}$ & $\begin{array}{c}\text { Topographical } \\
\text { Shielding }\end{array}$ \\
\hline 0.006222082 & 0.073792294 & 0.005457401 & 0.001668847 \\
\hline 0.001080377 & 0.027671989 & 0 & 0.029714612 \\
\hline 0 & 0.354167849 & 0 & 0.029714612 \\
\hline 0.026753333 & 0.187026381 & 0.109226667 & 0.115563229 \\
\hline 0.038861833 & 0.187026381 & 0 & 0.115563229 \\
\hline 0.016689 & 0.187026381 & 0 & 0.115563229 \\
\hline 0.055175 & 0.187026381 & 0 & 0.115563229 \\
\hline
\end{tabular}




\begin{tabular}{|c|c|c|c|}
\hline 0 & 0.187026381 & 0 & 0.324191451 \\
\hline 1.156296373 & 0.002195088 & 0 & 0.083125889 \\
\hline 0 & 0.045226131 & 0 & 0.083125889 \\
\hline 0 & 0.045226131 & 0 & 0.417540103 \\
\hline 0 & 0.036792155 & 0 & 0.417540103 \\
\hline 0 & 0.471916199 & 0 & 0.174954608 \\
\hline 0 & 0.011269335 & 0 & 0.284502 \\
\hline 0 & 0.011269335 & 2.6735 & 0.284502 \\
\hline
\end{tabular}

A correlation analysis was conducted. A correlation coefficent of 4-nonylphenol concentration with topographical shielding value was found to be insignificant. The negative correlation coefficent shows that there tends to be an inverse relationship between topogrpahic shielding and the 4-NP deposition, which supports client's hypothsis. However, the insignficant correlation might be due to missing factors in the topogrpahic shielding. For example, the surface of the terrain might have an impact on the concentration of the pullutant.

\subsection{Application Interface}

The development of the web application for the Wind Shadow Map was focused on clarifying and simplifying the problem for the user. The template of the application was from Esri. The application displayed the locations of the collected samples as well as other features such as the study area, lakes, counties of the Sierra Nevada, and the border of the Sierra Nevada.

The interface of the story map was designed so that users, regardless of age or skill, could navigate the web application easily. The user would see in the story map a couple of slides that introduce the problem and illustrate critical information regarding the 
project in a clear way. The first slide would introduce the 4NP toxic substance that jeopardizes wildlife in the Sierra Nevada mountains (Figure 6-2). The slide would also answer some questions, such as why 4NP is dangerous, where it could be found, what it is used for, and how it could harm human and aquatic creatures. The second slide would show the location of the study area and why it was chosen for this research. The third slide would add details about the location of samples. For example, how the scientist chose were to look for the sample. Moreover, this slide would have an interactive map to let the user explore the site and the data in order to better understand the project. The fourth slide would provide important information about the samples. Also, the slide would answer questions about the types of samples, explain why some of the points did not have 4NP concentration measurements, tell how the samples were collected from the site, and so forth. The fifth slide would explain the goal and the importance of the project. The last slide would show the result of the raster analysis and what the user could learn from the project. 


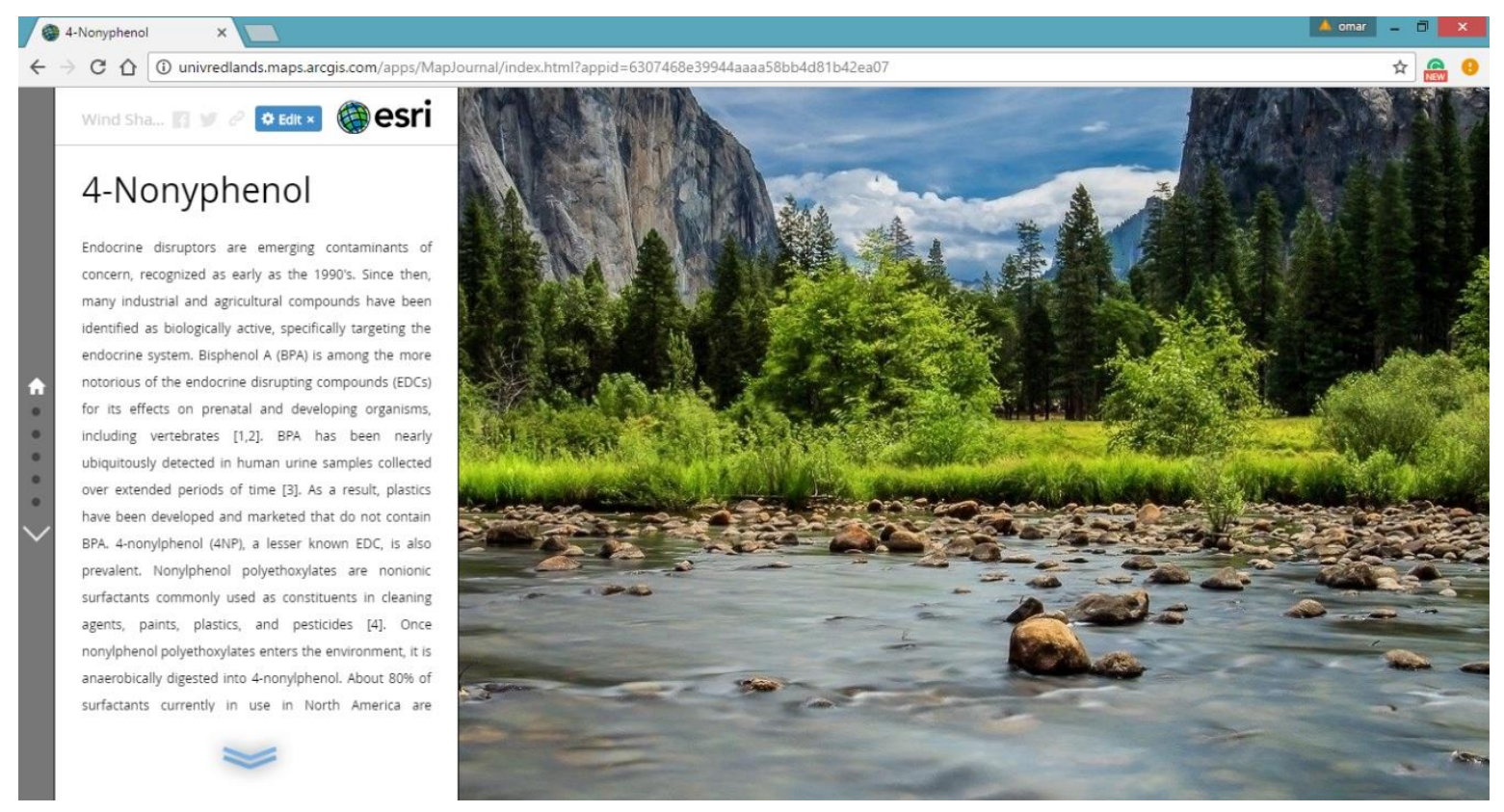

\section{Figure 6-2: The Interface of the Story Map.}

Each slide of the story map will contain specific information that is related to the 4NP, with maps to illustrate this information. Moreover, each map will contain a legend to describe its features, such as samples' locations, lakes, and the border of the Sierra Nevada conservancy. Also, each feature on the map will have a pop-up that presents essential information (figure 6-3). 


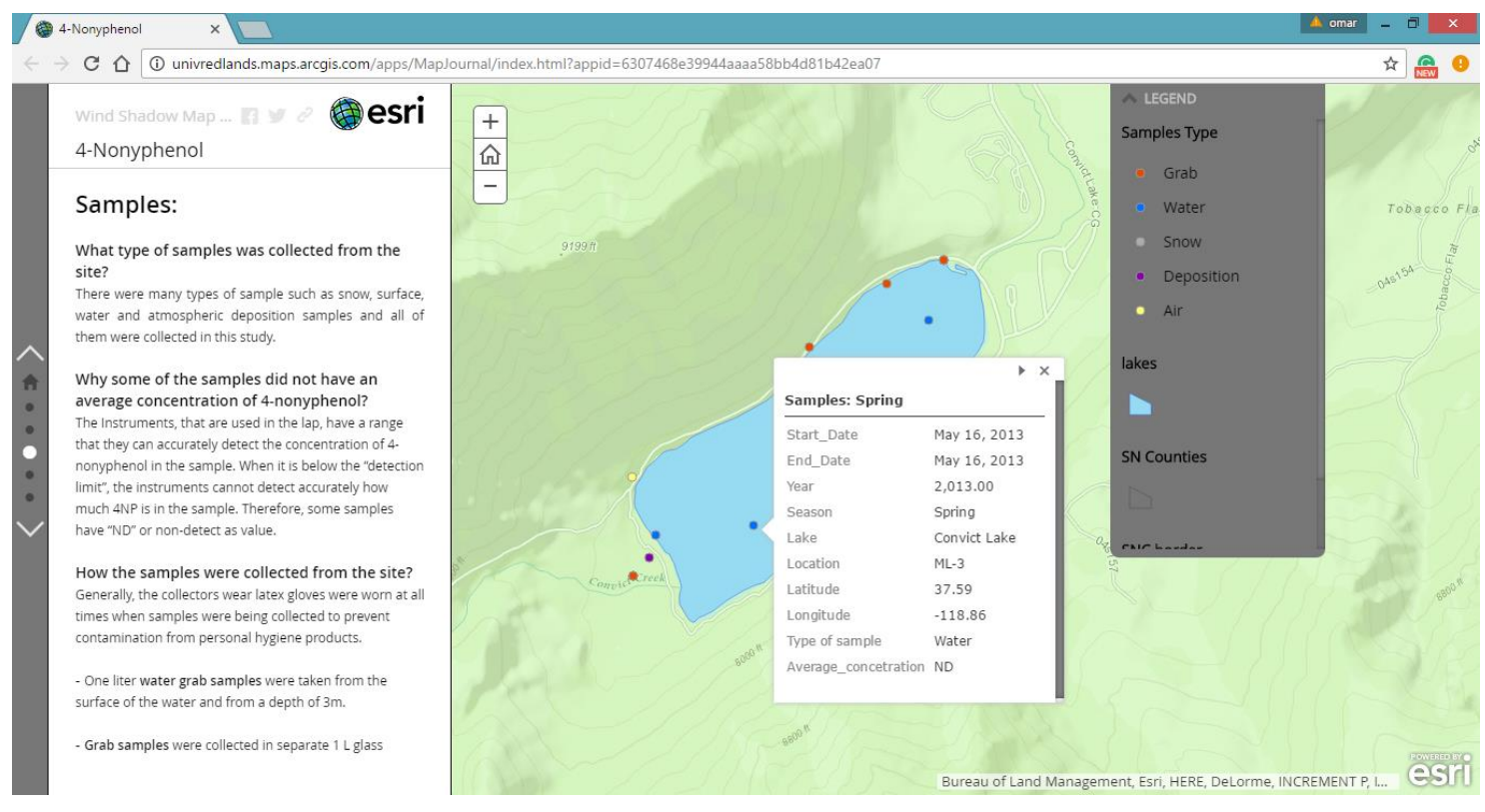

\section{Figure 6-3: The Legend of the Story Map.}

For the web application, the user would see the location of the study area with some features that would help the user visualize the location. Also, the web application would have five tools that would enhance the user experience with the data on the left side of the interface (figure 6-4). The first tool is Basemap Gallery. It would present a gallery of basemaps and allow the user to select one from the gallery. The second tool is Bookmark. It is a spatial bookmark, and it would store a collection of map view extents that were displayed in the application. Also, it would allow users to create and add their own spatial bookmarks through configuration. The third tool is Chart. It would display quantitative attributes from an operational layer as a graphical representation of data; this would make it easier for users to observe possible patterns and trends from within the raw data. The fourth tool is Query. It would allow the user to retrieve information from source data by executing a predefined query. The last tool is Summary. It would allow the user to 
summarize numeric attributes from a feature layer in the map that falls within the visible map extent.

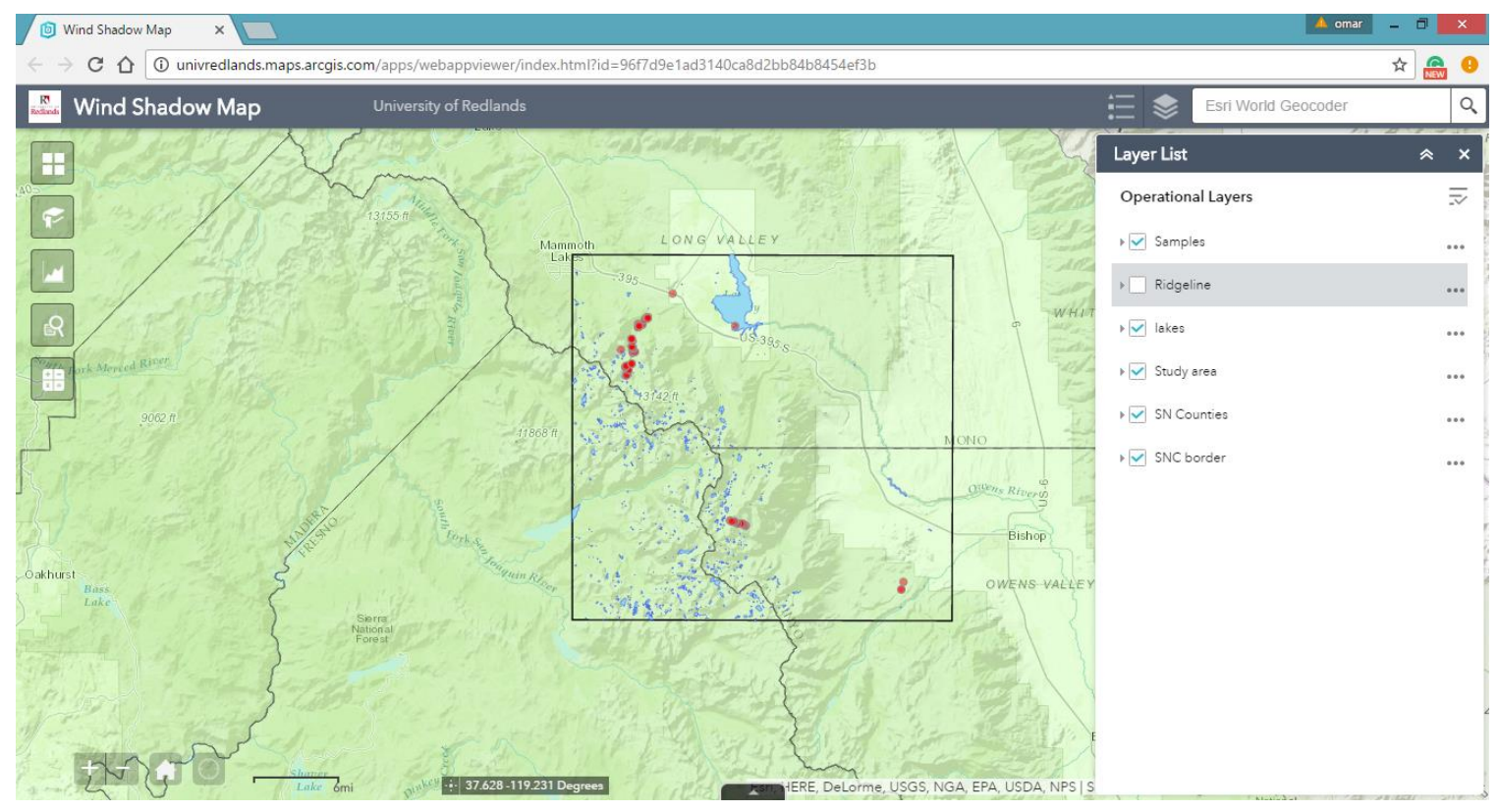

Figure 6-4: The Web Application Interface.

\subsection{Summary}

This chapter illustrated the results of the analysis and how to interpret the information displayed in the Excel spreadsheet. Also, the usefulness of the application and the functionalities of the user interface were discussed. The web application provides detailed information about 4-nonylphenol and the goal of the Wind Shadow Map. 


\section{Chapter 7 - Conclusions and Future Work}

This chapter describes the project conclusions in section 7.1, and section 7.2 addresses and suggests some ways to improve the project for future work.

\subsection{Project Conclusion}

The project had two goals. The first goal was to use locations of collected samples that show the concentration of 4-nonylphenol (4NP) in the Sierra Nevada mountains and develop a story map that could clearly demonstrate and present the problem so that the public would understand and realize how bad the situation is. All the slides of the story map were designed to let the user interact with the maps and read the information simultaneously. The second goal was to show how far the pollutants are transported by airborne particulate matter (PM) throughout the Sierra Nevada mountains. Calculating this involved an equation that depended on three factors that correlated with 4NP concentrations.

\subsection{Future Work}

The Wind Shadow Map Project could be improved in many aspects. Additions could be made to the first output, which is the story map. The story map could be updated and include more articles and information about the project. Also, the client could update the samples' location data and upload them to the story map. Furthermore, more analysis could be done with this project. However, currently the data attributes are missing some critical information; for example, the average concentration fields are not complete, but in the future, data could be added for analysis that would expand the project's reach. 
For the second output, the resolution of the DEM that was used in the project was ArcGrid 1 arc-second (approximately 30 meter) resolution. For future work, the resolution could be increased to ArcGrid 1/3 arc-second (approximately 10 meter) resolution to get more accurate results; however, the size of the file would likely be huge. For another improvement, the equation of the client could be developed further and incorporate more factors to it to obtain more reliable and realistic results. 


\section{Works Cited}

Bennasroune, A., Rojas, L., Foucaud, L., Goulaouic, S., and Laval-Gilly, P. (2012). Effects of 4nonylphenol and/or diisononylphthalate on THP-1 cells: impact of endocrine disruptors on human immune system parameters. International Journal of Immunopathology and Pharmacology, 25: 365-376.

Bennett, E. R., \& Metcalfe, C. D. (1998). Distribution of alkylphenol compounds in Great Lakes sediments, United States and Canada. Environmental Toxicology and Chemistry, 17, 1230-1235.

Beyer, A., Mackay, D., Matthies, M., Wania, F., \& Webster, E. (2000). Assessing long-range transport potential of persistent organic pollutants. Environmental Science \& Technology, 34, 699-703. Bonino, Enrico. (May 4, 2016). Mosquito-borne Disease. Retrieved from http://www.arcgis.com/home/item.html?id=7535c95667f040a2b3f5c95a9b57464e

Bradford, D. F., Heithmar, E. M., Tallent-Halsell, N. G., Momplaisir, G. M., Rosal, C. G., Varner, K. E., ... \& Riddick, L. A. (2010). Temporal patterns and sources of atmospherically deposited pesticides in alpine lakes of the Sierra Nevada, California, USA. Environmental Science \& Technology, 44, 4609-4614.

Brooks, A. N. (2012). Modeling the Impact of Terrain on Wind Speed and Dry Particle Deposition Using WindNinja and ArcGIS Spatial Analyst. Retrieved from http://inspire.redlands.edu/cgi/viewcontent.cgi?article=1164\&context=gis_gradproj

Esri. (2012, April 30). The Linked Burdens of Obesity and Diabetes. Retrieved from http://www.arcgis.com/home/item.html?id=d8f2281be8dd40ed84c6730deff9f829

Esri. (2016). Story Maps. Retrieved from https://storymaps.arcgis.com/en/faq/

Esri. (2016). ArcGIS for server. Retrieved from http://server.arcgis.com/en/server/latest/createweb-apps/windows/about-web-gis.htm

Flanagan, B. (2014, August 11). Ebola Outbreaks 1976-2015. Retrieved from http://www.arcgis.com/home/item.html?id=deb9d5151d954de5b3933294c911b67f

Flanagan, B. (2016, January 29). Zika Virus: 1947 to 2016. Retrieved from http://www.arcgis.com/home/item.html?id=9e9ca7c6957f4616a05a4331f99a0c22

Forte, M., Di Lorenzo, M., Carrizzo, A., Valiante, S., Vecchione, C., Laforgia, V., \& De Falco, M. (2016). Nonylphenol Effects on Human Prostate Non Tumorigenic Cells. Toxicology 357-358: 21-32.

Kim, Y. S., Hwang, K. A., Hyun, S. H., Nam, K. H., Lee, C. K., \& Choi, K. C. (2015). Bisphenol A and nonylphenol have the potential to stimulate the migration of ovarian cancer cells by inducing epithelial-mesenchymal transition via an estrogen receptor dependent 
pathway. Chemical Research in Toxicology, 28, 662-671.

King, M. (2012, December 11). Black Band and Yellow-Band Diseases in the Caribbean. Retrieved from http://www.arcgis.com/home/item.html?id=b44aa7d29860428a8caf582ded00e4c3

Kovner, K. (2009, December). Persistent Organic Pollutants: A Global Issue, a Global Response. Retrieved from https://www.epa.gov/international-cooperation/persistent-organicpollutants-global-issue-global-response\#pops

Lalah, J. O., Schramm, K. W., Henkelmann, B., Lenoir, D., Behechti, A., Günther, K., \& Kettrup, A. (2003). The dissipation, distribution and fate of a branched 14 C-nonylphenol isomer in lake water/sediment systems. Environmental Pollution, 122, 195-203.

Laws, S. C., Carey, S. A., Ferrell, J. M., Bodman, G. J., \& Cooper, R. L. (2000). Estrogenic activity of octylphenol, nonylphenol, bisphenol A and methoxychlor in rats. Soc. Toxicological, 54, 154-167.

Lepretti, M., Paolella, G., Giordano, D., Marabotti, A., Gay, F., Capaldo, A., ... \& Caputo, I. (2015). 4-Nonylphenol reduces cell viability and induces apoptosis and ER-stress in a human epithelial intestinal cell line. Toxicol in Vitro, 29, 1436-1444.

Lyons, R., Van de Bittner, K., \& Morgan-Jones, S. (2014). Deposition patterns and transport mechanisms for the endocrine disruptor 4-nonylphenol across the Sierra Nevada Mountains, California. Environmental Pollution, 195, 123-132.

Porse, C. (2013, April 18). Lyme Disease and Tick Surveillance in California. Retrieved from http://www.arcgis.com/home/item.html?id=8d99fb1135d1424f9d8a8711 acb7d459

Ren, L., Marquardt, M. A., \& Lech, J. J. (1997). Estrogenic effects of nonylphenol on pS2, ER and MUC1 gene expression in human breast cancer cells-MCF-7. Chemico-Biological Interactions, 104, 55-64.

Sierra Nevada Yellow-legged Frog. (2016, October 18). Retrieved from https://www.fws.gov/sacramento/es_species/Accounts/Amphibians-Reptiles/es_snyellow-legged-frog.htm

Soares, A., Guieysse, B., Jefferson, B., Cartmell, E., \& Lester, J. N. (2008). Nonylphenol in the environment: a critical review on occurrence, fate, toxicity and treatment in wastewaters. Environment International, 34, 1033-1049.

Szukalski, B. (2015, November 25). Bats Under Threat. Retrieved from http://www.arcgis.com/home/item.html?id=9b5f19e06a2b4aaba75844d147251d2b

TeamDev. (2015, February 18). Esca Disease of Grapevine. Retrieved from http://www.arcgis.com/home/item.html?id=c59ce5e000d94109b4f713157fe1532d 


\section{Appendix A. Python Script}

The code displayed here was created by Dr. Ruijin Ma to create the second and the third factors of the raster analysis.

\#C: \Users \Omar \Desktop \UR \F inal_DEM. img

C: \Users \Omar \Desktop \UR \F inal_Ridgel ine. img

$C: \backslash$ Users $\backslash$ Omar \Desktop \UR \results.img

\#Assuming the DEM file and the mask file have the exact same extent and spatial resolution

\#import gdalconst

\#import related modules

import numpy

import arcpy

import sys

import math

\#Get the parameters from a user (the command line)

demFName=sys . argv [1]

ridgeFName=sys. argv [2]

outFName=sys . argv [3]

demMeta=arcpy. Describe (demFName)

lower_left=demMeta.Extent. lowerLeft \#Lower left corner $x$, $y$. To find the exact value, use lower_left.X, lower_left.Y upper_left=demMeta. Extent . upperLeft

demRows=demMeta. height

\#know how many rows and

columns

demCols=demMeta. width

$\mathrm{xReso}=$ demMeta.meanCellWidth \#Spatial resolution along $\mathrm{x}$

yReso=demMeta.meanCellHeight \#Spatial resolution along $\mathrm{y}$

ridgeMeta=arcpy. Describe ( $r$ idgeFName)

ridgeRows=ridgeMeta. height

\#know how many rows

and columns

ridgeCols=ridgeMeta. width

\#Check to make sure the two files have the same dimensions

if demRows $\langle$ ridgeRows: \# or demCols $\langle>$ ridgeCols:

print 'The two files have different dimensions!'

sys.exit $(Q)$

demMat=numpy . matrix (arcpy . RasterToNumPyArray (demFName), dtype=numpy.float32) \#Read into float number for

calculation type of DEM float 32

ridgeMat=numpy . matrix (arcpy . RasterToNumPyArray ( $r$ idgeFName) , dtype=numpy . float32)

outMat=numpy . zeros ( (demRows, demCols, 2 ), dtype=numpy . float32

)

for irow in range(demRows):

for icol in range( $r$ idgeCols): 


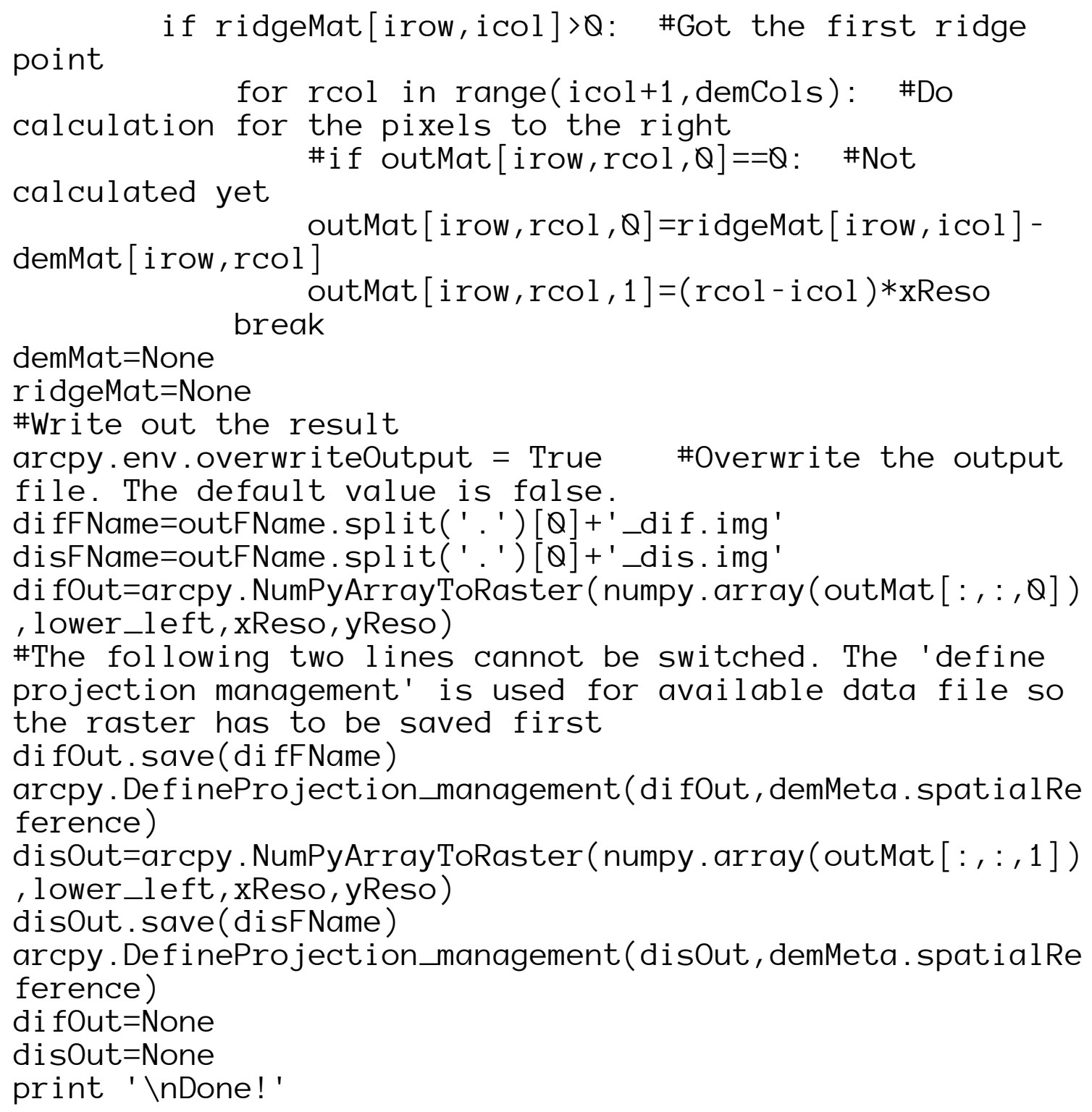

